\title{
Massage for Pain: An Evidence Map
}

\author{
Isomi M. Miake-Lye, $\mathrm{PhD}^{1,2}$ Selene Mak, MPH, ${ }^{1,2}$ Jason Lee, MD, MPH, \\ Tana Luger, PhD, MPH, ${ }^{2}$ Stephanie L. Taylor, $\mathrm{PhD}_{1}^{1,2}$ Roberta Shanman, MLS, \\ Jessica M. Beroes-Severin, BS, and Paul G. Shekelle, MD, PhD ${ }^{1}$
}

\begin{abstract}
Objectives: Massage therapy has been proposed for painful conditions, but it can be difficult to understand the breadth and depth of evidence, as various painful conditions may respond differently to massage. The authors conducted an evidence mapping process and generated an "evidence map" to visually depict the distribution of evidence available for massage and various pain indications to identify gaps in evidence and to inform future research priorities.

Design: The authors searched PubMed, Embase, and Cochrane for systematic reviews reporting pain outcomes for massage therapy. The authors assessed the quality of each review using the Assessing the Methodological Quality of Systematic Reviews (AMSTAR) criteria. The authors used a bubble plot to depict the number of included articles, pain indication, effect of massage for pain, and strength of findings for each included systematic review.

Results: The authors identified 49 systematic reviews, of which 32 were considered high quality. Types of pain frequently included in systematic reviews were cancer pain, low back pain, and neck pain. High quality reviews concluded that there was low strength of evidence of potential benefits of massage for labor, shoulder, neck, low back, cancer, arthritis, postoperative, delayed onset muscle soreness, and musculoskeletal pain. Reported attributes of massage interventions include style of massage, provider, co-interventions, duration, and comparators, with 14 high-quality reviews reporting all these attributes in their review.

Conclusion: Prior reviews have conclusions of low strength of evidence because few primary studies of large samples with rigorous methods had been conducted, leaving evidence gaps about specific massage type for specific pain. Primary studies often do not provide adequate details of massage therapy provided, limiting the extent to which reviews are able to draw conclusions about characteristics such as provider type.
\end{abstract}

Keywords: massage, pain, evidence map

\footnotetext{
${ }^{1}$ West Los Angeles Veterans Affairs Medical Center, Los Angeles, CA.

${ }^{2}$ Fielding School of Public Health, Department of Health Policy and Management, University of California, Los Angeles, Los Angeles, CA.

${ }^{3}$ UCLA Health, Los Angeles, CA.

${ }^{4}$ Southern California Evidence-Based Practice Center, RAND Corporation, Santa Monica, CA.

(C) Isomi M. Miake-Lye, et al. 2019; Published by Mary Ann Liebert, Inc. This Open Access article is distributed under the terms of the Creative Commons Attribution Noncommercial License (http://creativecommons.org/licenses/by-nc/4.0/), which permits noncommercial use, distribution, and reproduction in any medium, provided the original authors and the source are cited.
} 


\section{Introduction}

$\mathbf{P}$ AINFUL CONDITIONS ARE COMMON and a leading cause of morbidity. ${ }^{1,2}$ They are one of the most common symptomatic reasons for provider office visits. ${ }^{3}$ Different treatments have been proposed for painful conditions, including nonopioid drugs, opioids, surgery, and various types of complementary and integrative health modalities such as manual therapies, acupuncture, and mind-body methods. ${ }^{4}$

Therapeutic massage is one such proposed modality and has a number of desirable attributes - no special equipment is needed to deliver it; it can be given nearly anywhere, and there is a low likelihood of any serious harms. ${ }^{5-7}$ Massage has been the subject of more than 300 clinical trials and dozens of systematic reviews. For example, one review concluded that myofascial release therapy massage can be effective for treating plantar fasciitis, ${ }^{8}$ and another review found that soft tissue massage may be effective for shoulder pain. ${ }^{9}$

However, some reviews have found massage not effective. One review did not find clear benefits of massage over active treatment for fibromyalgia, low back pain, or neck pain. ${ }^{10}$ Another review reported that Swedish massage was not shown to improve outcomes in patients with fibromyalgia. ${ }^{11}$

As these examples suggest, there is heterogeneity both in the conditions for which massage is used, as well as in the therapy itself. The term "massage therapy" encompasses many techniques, and the type used may vary by a patient's needs and physical conditions. ${ }^{7}$ Common types include Swedish massage, deep tissue massage, sports massage, and chair massage. ${ }^{12,13}$ Therapeutic massage can be provided by a variety of practitioners, including licensed massage therapists, physiotherapists, chiropractors, folk healers, and reflexologists. ${ }^{14}$ These practitioners can differ in philosophy or approach to massage, as well as the duration and intensity of training in massage treatments. In general, patients are treated using touch to manipulate the muscles and other soft tissues of the body. ${ }^{15-18}$

Because individual trials and systematic reviews of individual trials often focus on particular types of massage or specific painful conditions (back pain, neck pain, etc.), it can be difficult to see the breadth and depth of evidence, as various painful conditions may respond differently to therapeutic massage, and distinct types of massage involve unique approaches to manipulating muscles and soft tissue. Thus, the authors undertook to create an evidence map, which is a technique that allows us to visually depict the distribution of evidence available to provide an overview of a broad research field that describes the volume, nature, and characteristics of research in a particular field, often in a visual summary. ${ }^{19}$ As such an evidence map does not seek to critically analyze or synthesize the evidence on effectiveness for specific clinical indications. This approach is useful to identify the gaps in evidence and inform future research priorities.

\section{Materials and Methods}

This evidence map is reported according to Preferred Reporting Items for Systematic Reviews and Meta-analyses guidelines (Supplementary Table S1). ${ }^{20}$ This review is part of a larger review commissioned by the Department of Veterans Affairs, funded by the Veterans Affairs Quality Enhancement Research Initiative. ${ }^{21}$

\section{Data sources and searches}

The authors conducted broad searches from database inception through July 10, 2018 using terms related to pain and massage in three databases: PubMed, Embase, and the Cochrane Database of Systematic Reviews and Other Reviews (see Supplementary Data for full strategy). The authors restricted their searches to English language publications and systematic reviews.

\section{Study selection}

Each article title was screened independently by two authors for relevance; any title chosen by either reviewer was included in the abstract screen. When titles were ambiguous they were included for further review. Abstracts were then reviewed in duplicate with any discrepancies resolved through team discussion. To be included, abstracts or titles needed to be relevant to massage, mention pain or a pain-related condition (e.g., headache), and describe a systematic review. The following patient population, intervention, comparator, outcome, timing, and setting (PICOTS) guided study selection.

\section{Patient population: any pain-related condition or indication}

Intervention. Massage was as self-reported and defined by the authors of eligible systematic reviews. The authors did not develop or apply any separate definition or criteria to determine if an intervention was massage. Alternate terms Tui $\mathrm{Na}$ or shiatsu were also included. Massage applied as prevention, as in the case of perineal massage, was not included, to distinguish between prevention and treatment of pain. Massage conducted by lay persons, for example, caretakers or self-massage, was not included.

\section{Comparator. Any.}

Outcome. Pain outcomes were required to be reported separately. If pain was part of a composite score of wellbeing, for instance, this would be excluded if pain was not reported separately.

\section{Timing. Any.}

\section{Setting. Any.}

Next, full text publications for all included abstracts were screened. Each publication had to be a unique systematic review reporting pain outcomes for massage interventions. Reports or publications from the same review or review updates were included, but data were extracted and counted only once. Systematic reviews were eligible if they covered additional outcomes or other interventions as long as the results of massage for pain were reported separately for at least two included massage studies.

\section{Data extraction}

One reviewer abstracted data for each included systematic review and a second reviewer verified it. Abstracted data included the following: number of studies in the review with massage as the intervention and pain as an outcome; total number of studies included in the review; descriptions of the massage style, provider, co-interventions, duration, and comparators; pain type; main findings relevant to massage 
for pain; and whether the systematic review focused solely on massage as the intervention or included a variety of interventions, of which massage was one.

\section{Quality assessment of included systematic reviews}

Each systematic review was assessed using a modified version of the Assessing the Methodological Quality of Systematic Reviews (AMSTAR) criteria. ${ }^{22}$ This 11 -item tool assesses the methodological quality of systematic reviews (see full modified tool in Appendix A1). The authors relaxed four criteria on quality assessment: (1) the search strategy was not required to have supplemental searches beyond the two or more sources being searched; (2) reviews were not required to provide a list of their excluded studies; (3) narrative publication bias discussions were acceptable for systematic reviews not using quantitative methods; and (4) documented sources of support were not required for the included individual studies.

While there is no agreed upon threshold for AMSTAR criteria above which a systematic review would be considered "high quality," the authors used a score of 9 or higher for their purposes. Thus, studies could miss a maximum of two criteria and still be considered "high quality."

\section{Strength of evidence}

To assess strength of evidence for high-quality systematic reviews (AMSTAR scores of 9 or above), the authors used the GRADE approach, ${ }^{23}$ which takes into account study design limitations, inconsistency, indirectness, and imprecision in primary study results to assess the body of evidence contributing to a particular finding. In most cases, these findings were already described with levels of evidence in the original systematic reviews, but in the cases where this was not provided, the team assessed the GRADE strength of evidence based on the description of findings provided in the systematic review and discussed as a group to reconcile. The authors added a fifth category "unable to determine strength of evidence" to classify reviews that had sources of bias that may affect the results and conclusions of these reviews. Hence, the five categories are as follows:

(1) High strength of evidence: The authors are very confident that the true effect lies close to that of the estimate of the effect. Further research is unlikely to change their confidence in the estimate of effect.

(2) Moderate strength of evidence: The authors are moderately confident in the effect estimate. The true effect is likely to be close to the estimate of the effect, but there is a possibility that it is substantially different. Further research is likely to have an important impact on their confidence in the estimate of effect and may change the estimate.

(3) Low strength of evidence: Their confidence in the effect estimate is limited. The true effect may be substantially different from the estimate of the effect. Further research is very likely to have an important impact on their confidence in the estimate of effect and is likely to change the estimate.

(4) Very low strength of evidence: The authors have very little confidence in the effect estimate. The true effect is likely to be substantially different from the estimate of effect. Any estimate of effect is very uncertain.

(5) Unable to determine the strength of evidence: The authors did not classify reviews with AMSTAR quality scores of 8 or lower because their methodology makes interpretation of their reported findings difficult, as sources of bias may be affecting the results and conclusions drawn.

\section{Data synthesis}

Their evidence mapping process resulted in a visual depiction of the evidence for massage for pain, as well as an accompanying narrative with ancillary figures and tables. As noted by Ballard and Montgomery, this type of overview of reviews faces four conditions distinct from a traditional systematic review of individual trials or studies: (1) amount of overlap between systematic reviews included; (2) included reviews falling partially out of scope; (3) quality assessments, including methodological quality of primary studies within included reviews, of included reviews themselves, and of evidence across included systematic reviews; and (4) included reviews being up-to-date. ${ }^{24}$ It was not feasible for their team to assess the overlap between included systematic reviews, and this issue is explored in the Discussion section. For reviews that fell partially out of scope, the authors extracted and synthesized only those findings related to both massage and pain, as described in the Data Extraction section above. Relating to quality assessments, the authors relied on the assessments of review authors for methodological quality of primary studies, used AMSTAR for included reviews, and used GRADE for assessment of evidence across reviews. Finally, the authors did not take actions to update included reviews.

Evidence map. The visual depiction uses a bubble plot format to display information for each systematic review on four dimensions. The evidence map figure also allows the reader to visualize gaps in the literature base, where there is no or little evidence for particular pain indications. The four dimensions are as follows:

(1) Number of articles (bubble size): Each review bubble's size is directly proportional to the number of primary research studies on the effect of massage for pain in that review (i.e., bubble size grows incrementally with each additional included study).

(2) Pain type (bubble label): Each bubble is labelled with the pain indication(s) in the review.

(3) Effect of massage for pain (x-axis): The authors grouped reviews into one of five categories of findings they reported on for massage for pain. Those reporting massage as more beneficial than the comparator were included in the "potentially better" group, those reporting massage as less beneficial than the comparator were included in the "potentially worse" group, those suggesting insufficient evidence to draw clear conclusions about the effectiveness of massage for pain were included in the "unclear" group, those with findings that varied within the review (e.g., some studies found no difference between massage and comparators for cancer pain, while others found potential benefits of 
FIG. 1. Literature flow chart. *Results from searches described in Supplementary Table S1.

**Article reference list includes additional references cited for background and methods.

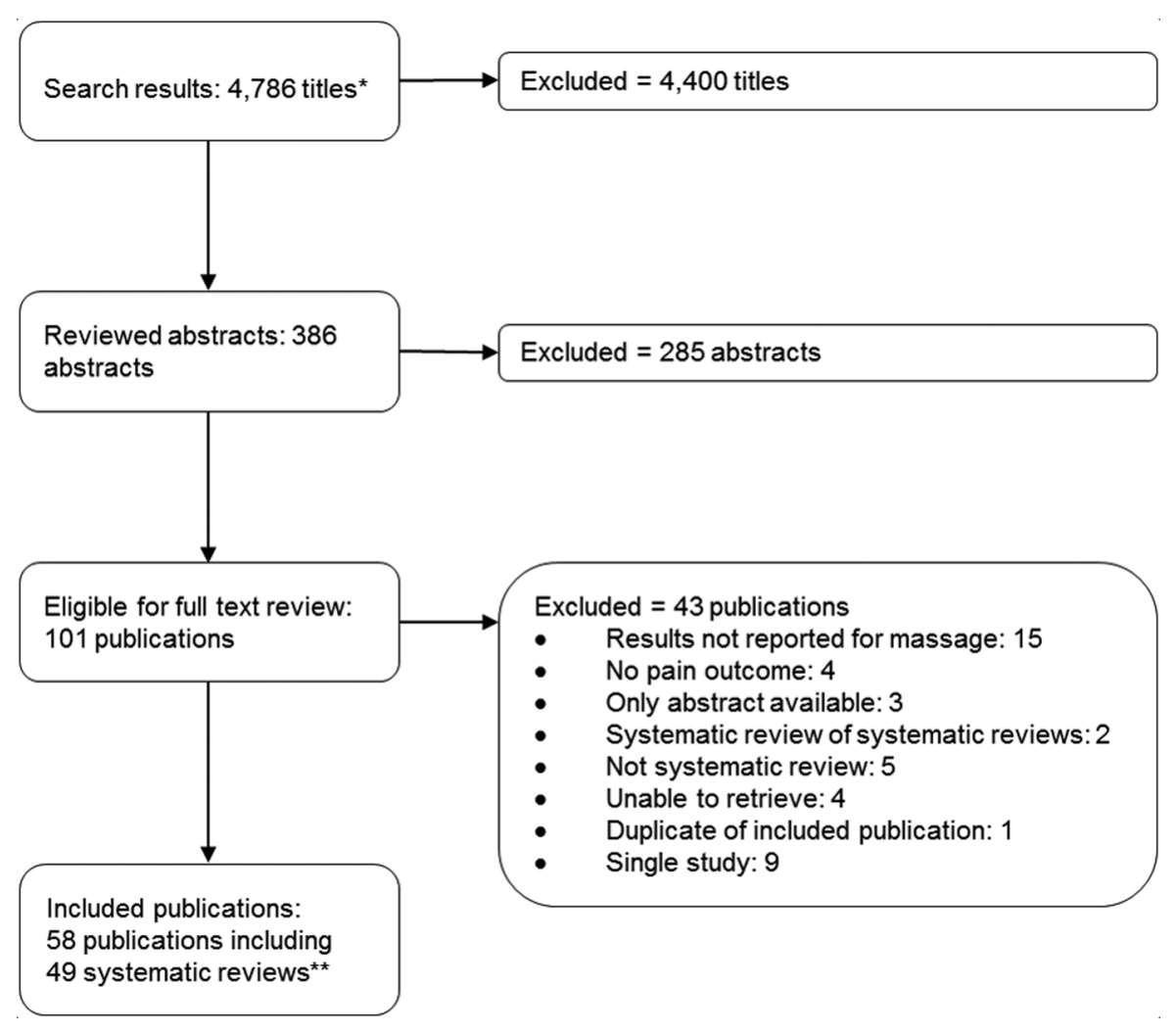

massage over some comparators for cancer pain) were included in the "mixed results" group, and those that were unable to detect differences between massage and the comparator for pain were included in the "no difference" group. Each systematic review had one overall finding included in the bubble plot; if a review had multiple consistent findings it was added to that appropriate group, whereas reviews with multiple conflicting findings were included in the "mixed results" group.

(4) Strength of findings ( $y$-axis, color): As described above, high-quality systematic reviews (AMSTAR scores of 9 or above) were sorted into five categories according to the GRADE approach: high strength of evidence, moderate strength of evidence, low strength of evidence, very low strength of evidence, or unable to determine the strength of evidence.

Narrative synthesis. The narrative synthesis expands upon the visual evidence map to provide more details from the included systematic reviews. These include descriptions of the findings, the features of massage therapy, and the types of pain.

\section{Results}

\section{Literature flow}

Their searches identified 4786 titles as potentially relevant for this evidence map. From these titles, 386 titles were included for abstract review. Their screen of abstracts excluded 285 abstracts because they did not mention pain as an outcome, did not mention therapeutic massage as an in- tervention, used a study design other than systematic review, or some combination of these factors. When reviewing full texts, there were 43 publications that did not meet inclusion criteria upon further inspection. Fifteen publications did not report the results for massage separately from other interventions or the intervention did not include massage, nine publications with broader scopes only included one massage for pain study, four publications did not report pain as an outcome, five publications were nonsystematic reviews or commentaries, four publications were not retrievable, three publications were only available in abstract form, two were systematic reviews of systematic reviews, and one was a duplicate of another included publication. See the Literature Flow in Figure 1.

From the 101 publications included in the full text review, the authors included 58 publications that discussed 49 systematic reviews. Nine publications discussed systematic reviews that were overlapping with included systematic reviews. ${ }^{18,25-31}$ This includes older iterations of systematic reviews, the updates for which had been included, 25,26,30,31 as well as instances where multiple publications were produced from the same systematic review effort. ${ }^{18,27-29,32}$ Below the authors describe the following about the included reviews: the quality of the reviews, how they described the components of massage-related interventions included in their reviews, and how their overall findings are represented in the evidence map.

\section{Quality of included systematic reviews}

Of the 49 systematic reviews included, 10 reviews met all 11 modified AMSTAR criteria, twelve reviews met 10 criteria, and 10 reviews met 9 criteria (see Table 1, which 


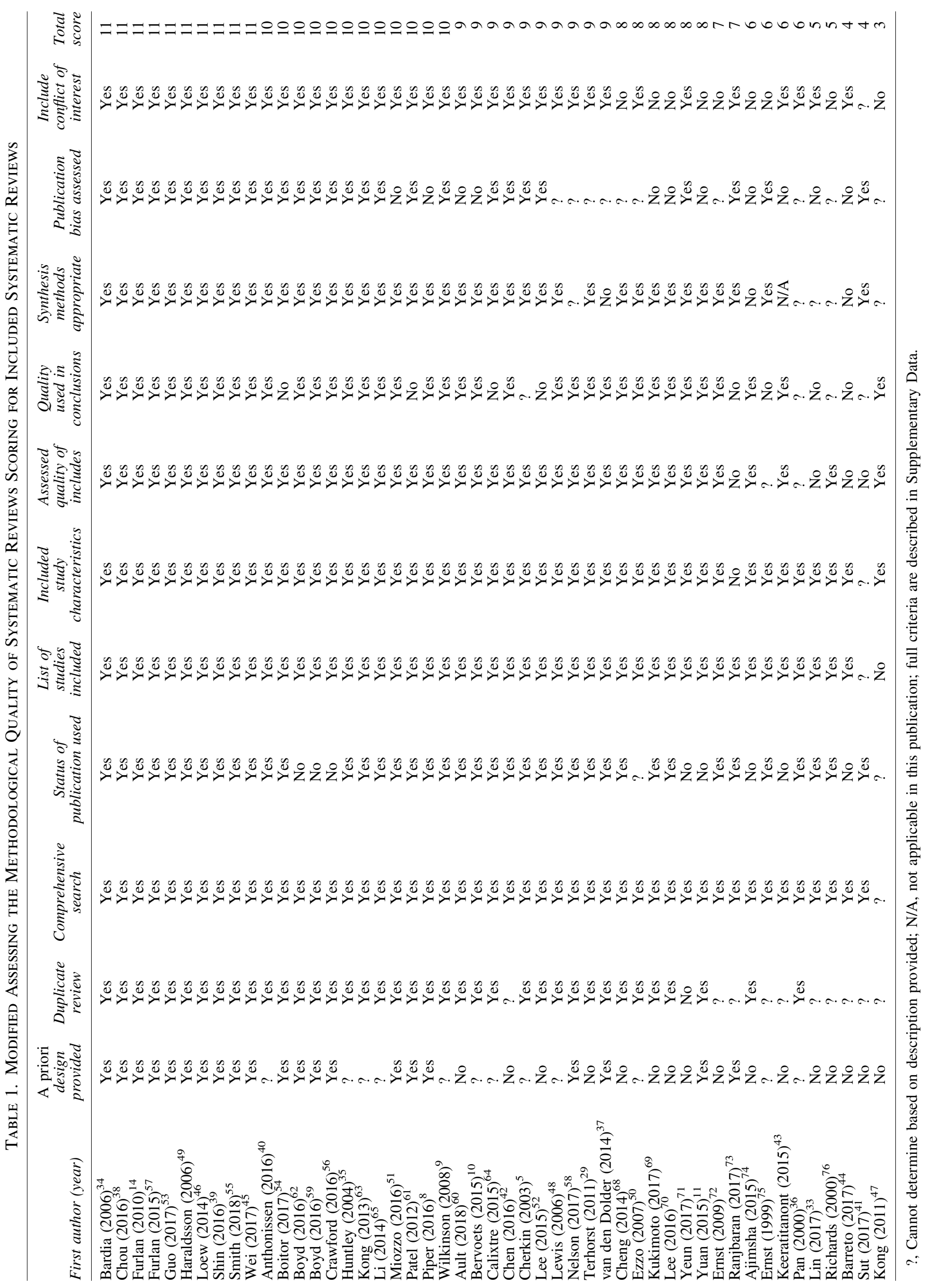


delineates how each included review scored on the AMSTAR criteria). The authors considered these 32 systematic reviews to be of high quality. The other 17 systematic reviews were of lower quality and met 8 AMSTAR criteria $(n=6), 7$ criteria $(n=2), 6$ criteria $(n=4), 5$ criteria $(n=2)$, or 3 criteria $(n=1)$. Nearly all systematic reviews $(n=48)$ conducted a comprehensive search, and 47 systematic reviews provided a list of included studies with descriptions of their characteristics. The least often met criterion was to provide an a priori design $(n=21)$.

\section{Intervention components described in included systematic reviews}

Given the heterogeneity of massage therapies, accurate and detailed reporting about these interventions is necessary to

Table 2. Intervention Components Described in Included Systematic Reviews

First author (year) Focused on massage Style Provider Co-interventions Duration Comparators

High quality systematic reviews (AMSTAR score 9 or higher)

Bardia $(2006)^{34}$

Chou $(2016)^{38}$

Furlan (2010) 14

Furlan $(2015)^{57}$

Guo $(2017)^{53}$

Haraldsson $(2006)^{49}$

Loew (2014)

Shin $(2016)^{39}$

Smith (2018) 55

Wei (2017) ${ }^{45}$

Anthonissen (2016) ${ }^{40}$

Boitor (2017) ${ }^{54}$

Boyd (2016) ${ }^{62}$

Boyd (2016) ${ }^{59}$

Crawford (2016) $)^{56}$

Huntley (2004) ${ }^{35}$

Kong (2013) ${ }^{63}$

Li (2014) ${ }^{65}$

Miozzo (2016) ${ }^{51}$

Patel (2012) ${ }^{6}$

Piper (2016)

Wilkinson $(2008)^{9}$

Ault (2018)

Bervoets (2015) ${ }^{10}$

Calixtre $(2015)^{64}$

Chen (2016) ${ }^{42}$

Cherkin $(2003)^{5}$

Lee $(2015)^{5}$

Lewis (2006) ${ }^{48}$

Nelson (2017) ${ }^{58}$

Terhorst $(2011)^{29}$

van den Dolder $(2014)^{37}$

Other systematic reviews (AMSTAR score 8 or lower)

Cheng (2014) ${ }^{68}$

Ezzo (2007)

Kukimoto $(2017)^{69}$

Lee $(2016)^{70}$

Yeun $(2017)^{71}$

Yuan (2015) ${ }^{11}$

Ernst (2009) ${ }^{72}$

Ranjbaran (2017) ${ }^{73}$

Ajimsha $(2015)^{74}$

Ernst (1999) ${ }^{75}$

Keeratitanont $(2015)^{43}$

Pan (2000) $)^{36}$

Lin $(2017)^{33}$

Richards (2000) ${ }^{76}$

Barreto (2017)

Sut $(2017)^{41}$

Kong (2011) ${ }^{47}$

-, Yes; o, no.

AMSTAR, Assessing the Methodological Quality of Systematic Reviews. 
understand what is being included and synthesized in systematic reviews. However, the systematic reviews presented in this study varied in the amount of detail they reported in describing the massage performed in primary studies and how they reported this information (see Table 2 for an overview of which components were described by each included review). Of the 32 high-quality systematic reviews, all 6 intervention components were reported in 14 reviews; 4 of the 17 reviews with lower AMSTAR ratings reported on all 6 intervention components.

Thirty-eight of the systematic reviews focused solely on interventions they categorized as massage, while the other 11 included other types of similar interventions in a broader grouping, with the most common group being some type of complementary and integrative medicine..$^{5,14,29,33-36}$ Other broader groups of interventions included exercise, ${ }^{37}$ noninvasive treatments, ${ }^{38}$ aromatherapy, ${ }^{39}$ and conservative treatments, ${ }^{40}$ which included silicone gel application, ultrasound, pressure therapy, hydration, and combinations of therapies in addition to massage.

A description of massage style was included in all but three of the systematic reviews. There was considerable variability both within individual systematic reviews, as well as between reviews in what is considered to be massage. Six reviews included studies of particular types of massage as follows: aromatherapy massage, ${ }^{41,42}$ traditional Thai massage, ${ }^{43}$ Swedish massage, ${ }^{44}$ Tui $\mathrm{Na}^{45}$ and deep transverse friction massage. ${ }^{46}$ Another two systematic reviews included studies of therapeutic massage; however, they included a different range of therapies within this categorization, with one including chiropractic management in their review, ${ }^{47}$ while the other explicitly excluded manipulation techniques. ${ }^{48}$ Other systematic reviews had general inclusion criteria for massage interventions, and there was variety in whether related interventions like reflexology or manipulation techniques were included. Some common massage types included Swedish massage, myofascial therapies, Shiatsu, Chinese traditional massage, Thai massage, slow stroke massage, and more general descriptions of massage. As noted in one high-quality systematic review that focused on massage as the sole intervention, ${ }^{49}$ most of the primary research studies "lacked a clear definition, description, or rationale for massage, the massage technique, or both." Abridged descriptions for each systematic review are provided in the evidence tables (Appendix Table A1).

The feature of massage least often described in the systematic reviews was the provider of the massage therapy. Twenty-five systematic reviews did not provide descriptions of the massage provider. Multiple reviews mentioned that primary research study descriptions often did not provide this information, which affected the reviewers' abilities to abstract and report on provider information systematically. ${ }^{34,49,50}$

Forty-seven systematic reviews included descriptions of the other interventions against which massage was compared (i.e., comparators), and 46 reviews described the duration or timing of massage treatment. Comparators varied between trials, including no treatment; usual care; active treatment that is not another form of massage, such as exercise therapy or relaxation therapy; and inactive treatment, such as sham or rest. Often there was considerable heterogeneity in comparators within systematic reviews. Forty-two reviews included descriptions of co-interventions or reported that they excluded studies with co-interventions. Comparators, duration, and co-interventions were most often reported for each primary study included in the review, with variability between these primary studies. Some reviews, like the one by Furlan et al., ${ }^{14}$ parsed out findings for different comparators, while many did not.

\section{Evidence map}

Figure 2 presents the results of the evidence mapping process. The evidence map displays each of the 49 included systematic reviews as bubbles. As noted in the Materials and Methods section, the bubble label represents the pain indication in that review. The bubble size denotes the number of primary studies included in that review specifically related to massage for pain. Primary studies may be included in multiple systematic reviews. Each bubble was plotted according to the strength of the findings for massage for pain ( $y$-axis, color) and the effect massage had on pain ( $x$-axis). The evidence tables provide details of included systematic reviews (Appendix Table A1).

\section{Specific findings from systematic reviews in the evidence map}

Of the 49 systematic reviews included in the map, none described moderate- or high-strength findings, 14 highquality reviews described low-strength findings, 18 highquality reviews described very low-strength findings, and 17 reviews were of lower quality, and thus, authors were not able to determine the strength of their findings due to multiple potential sources of bias. The authors present details in the Evidence Table (Appendix Table A1).

Low-strength findings from 14 systematic reviews. Fourteen high-quality systematic reviews found low-strength findings, which according to the GRADE approach means that there is limited confidence in the effect estimate and "the true effect may be substantially different from the estimate of the effect." 23 Of the 14 reviews in this group, 8 reviews summarized their findings using language consistent with the GRADE approach, and the authors relied on their strength of evidence assessment for their overall findings. ${ }^{14,37,38,40,42,51-53}$ The authors assigned low strength to the overall findings in three reviews that couched their findings in the need for further research and described uncertainty due to several limitations in the primary research, ${ }^{8,54,55}$ as these descriptions most closely aligned with a low strength of evidence level. Finally, three reviews had multiple findings that were not aggregated. ${ }^{56-58}$ The authors assigned a GRADE strength of evidence to their overall findings that most closely aligned with the most prevalent strength of evidence they had assigned to their multiple findings.

Nine of the 14 reviews found that massage was potentially better than the comparator in a variety of conditions: postoperative pain, ${ }^{51,54}$ shoulder pain, ${ }^{37}$ pain during labor, ${ }^{55}$ low back pain, ${ }^{32,38}$ cancer-related pain, ${ }^{52}$ delayed onset muscle soreness, ${ }^{53}$ and musculoskeletal pain. ${ }^{56}$ One review broadly studying massage for many painful conditions also reached low strength findings that massage can be beneficial across multiple conditions. ${ }^{8,56}$ Four systematic reviews described mixed results, with massage sometimes performing 
FIG. 2. Evidence map of systematic reviews describing the effect of massage for pain. Cervical rad., cervical onset of muscle soreness; Dysmen, dysmenorrhea; Fibro., fibromyalgia; LBP, low back pain; Multi, multiple conditions described; Musculo., musculoskeletal; Pall., palliative; Post-op., postoperative; TMJ, temporomandibular disorder. radiopathy; DOMS, delayed

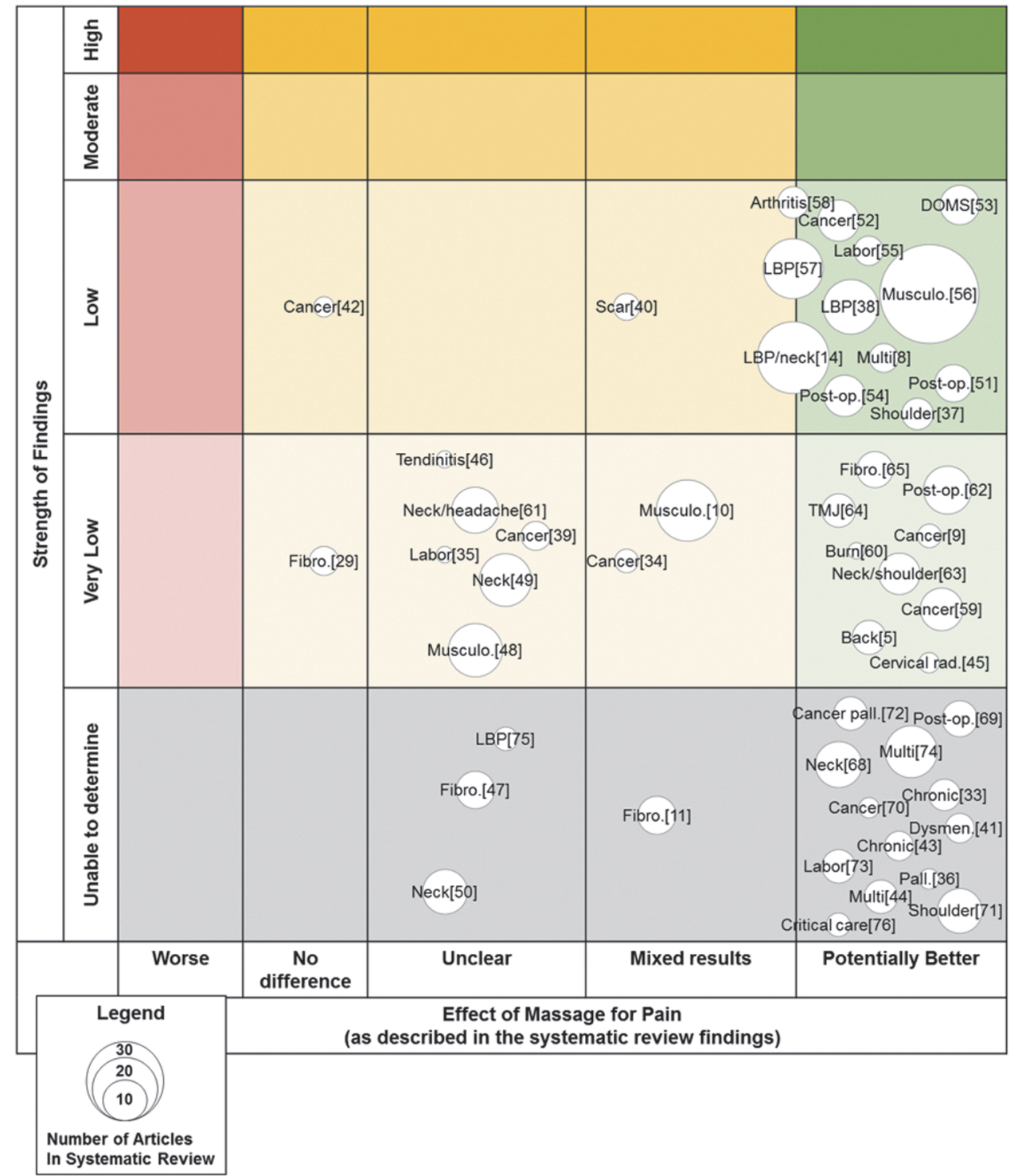

better than the comparator, with low-strength findings (see specific findings in the Evidence Tables, Appendix Table A1). ${ }^{14,40,57,58}$ One review focused on massage for low back pain ${ }^{57}$ and found that massage showed potential benefit compared to inactive controls for pain in the short term, but not in the long-term follow-up. This review also found that massage showed potential benefit compared to active controls for pain in both short and long-term follow-up. A second review from the same group looked more broadly at complementary and alternative medicine for back and neck pain and found that massage was superior to placebo, no treatment, relaxation, or physical therapy. ${ }^{14}$ These findings were varied based on pain acuity and sometime by type (e.g., chronic low back pain compared with nonspecific low back pain). The third review with mixed results described evidence related to massage for arthritis, ${ }^{58}$ with massage showing potential benefits compared to inactive treatments but unclear benefits compared with other types of treatment. The final review in this group examined a range of conservative treatments and described reductions in pain for burn scars in the massage groups in two studies reporting pain outcomes, one of which compared massage to usual care, while the other study did not include a comparator. ${ }^{40}$ The final review reaching low strength findings found no statistical difference between massage and the comparator groups in a pooled analysis of three studies with cancer pain outcomes. $^{42}$

Very low-strength findings from 18 systematic reviews. Eighteen high-quality systematic reviews found very low-strength findings, which according to the GRADE approach means that there is "very little confidence in the effect estimate. The true effect is likely to be substantially different from the estimate of effect. Any estimate of effect is very uncertain." ${ }^{23}$ Of the 18 reviews in this group, 11 reviews summarized their findings using language consistent with the GRADE approach, and the authors relied on their strength of evidence assessment for their overall findings. ${ }^{10,34,35,39,45,46,49,59-62}$ The authors assigned low strength to the overall findings in seven reviews that used language that characterized their findings as preliminary or weak, or described wide variability in the evidence, $, 9,29,48,63-65$ as 
these descriptions most closely aligned with a very low strength of evidence level.

Of the reviews with very low-strength findings, nine reviews suggested that massage may be better than the comparator for pain related to a variety of conditions, including fibromyalgia, ${ }^{65}$ temporomandibular disorder, ${ }^{64}$ neck and shoulder, ${ }^{63}$ cancer, ${ }^{9,59}$ postoperative pain, ${ }^{62}$ burn pain, ${ }^{60}$ cervical radiopathy, ${ }^{45}$ and back pain. ${ }^{5}$ Two reviews with very low-strength findings described mixed results for musculoskeletal pain ${ }^{10}$ and cancer pain. ${ }^{34}$ These reviews described studies that were split between showing no difference and improvements in pain with massage treatments, with small sample sizes and other methodological considerations creating additional uncertainty noted by the review authors. Six reviews found very low strength of evidence demonstrating unclear findings for massage. $35,39,46,48,49,61$ These reviews all described the need for more research before any conclusions could be drawn for topics, including tendinitis, labor, neck pain, headache, cancer, and other musculoskeletal conditions. The final review with very lowstrength findings suggested that there was no difference between massage and the included comparators-standard care, discussion groups, yoga, lymph drainage, relaxation, and sham transcutaneous electrical nerve stimulation (TENS) for fibromyalgia pain. ${ }^{31}$

Description of remaining 17 systematic reviews. Seventeen systematic reviews were scored as having not met three or more quality criteria using AMSTAR. This indicates that there were flaws in the reporting or methodology of these systematic reviews that make it difficult to determine how their findings should be interpreted. As such, these findings were not able to be categorized by strength, and the conclusions drawn in these systematic reviews should be interpreted with caution. To the extent that higher quality systematic reviews have covered the same topics, these findings may be interpreted with more confidence than the findings in this group of lower quality reviews. Many topics in this group have been the subject of higher quality systematic reviews included in this evidence map, including neck, fibromyalgia, low back, cancer, shoulder, labor, and postoperative pain.

\section{Discussion}

This evidence mapping process found a range of evidence on massage for pain, including 49 systematic reviews, and identified gaps in evidence, particularly relating to details of massage therapy provided. Findings from 12 high-quality reviews reached low strength findings that there may be potential benefits of massage for pain indications, including labor, shoulder, neck and low back, cancer, postoperative, arthritis, delayed onset muscle soreness, and musculoskeletal pain. One high-quality systematic review broadly studying massage for many painful conditions also reached low strength findings that massage can be beneficial across multiple conditions. ${ }^{8,56}$ In addition, nine high-quality systematic reviews reached very low strength findings of potential benefits of massage for pain indications, including fibromyalgia, temporomandibular disorder, burn, and cervical radiopathy. However, no findings were rated as moderate or high strength, suggesting that there were methodological limitations pervasive in this literature and that more research is needed to establish confidence in the effect of massage for pain. Of the lower quality reviews, some overlapped in scope with higher quality reviews while others did not, suggesting that these topics be revisited with strong synthesis methodology before conclusions can be drawn from the findings. None of the reviews included in this evidence map found massage to be worse than the comparator.

Systematic review authors found that primary studies often do not provide adequate details of the massage therapy provided, especially in the descriptions of provider type. The lack of information provided about the practitioner affected the reviewers' abilities to abstract and report on provider information systematically. ${ }^{34,49,50}$ In addition, terminology is unclear, with no standardized definition of massage types or what specific therapies are included under the umbrella term "massage." Some reviews included terms such as "manipulation reflexology," "cross fiber friction," and "connective tissue release techniques," while others used the general term "Western massage" and "comprehensive massage." Given this lack of standardization and reporting, the authors are unable to determine if there are particular types of massage that are more or less effective for painful conditions more broadly or if there are specific massage types that have distinct utility for particular painful conditions.

Their approach has several limitations inherent to evidence maps and other evidence synthesis methods involving the review as the unit of analysis, rather than synthesizing data from individual studies. ${ }^{24}$ Included systematic reviews that cover similar topic areas may have large overlap in terms of the primary studies they include, but because their unit of analysis is systematic reviews, rather than primary studies, the inclusion of the same studies in multiple reviews does not create issues of bias, rather the potential for bias arises when multiple reviews reach the same conclusions and create the appearance of more evidence for a particular topic than there actually is. Thus, in interpreting the evidence map, it is imperative that the bubbles not be interpreted as additive. Rather, multiple bubbles with differing results may suggest the maturing of evidence in a certain area when a newer and larger review draws a different conclusion, or may highlight the nascent or unclear nature of evidence in concurrent reviews that reach different findings. Another common limitation anticipated by Ballard was that many of their reviews covered material out of their evidence map scope. To address this concern, the authors extracted only the information relevant to pain and massage. The range of quality of identified systematic reviews was assessed using AMSTAR, and findings were discussed separately for lower quality reviews. Thus, the potential for bias that these lower quality reviews introduce rendered us unable to determine the strength of their findings. And while the authors did rely on the strength of evidence provided by the high-quality reviews whenever possible, it is possible that their determination of strength of evidence may have been different from those determined by the authors. The authors did review and agree with all GRADE strength of evidence assignments reported in the map based on the descriptions of the evidence presented in the reviews, but the authors did not retrieve all primary studies, and thus must caution readers that the authors have not conducted their own independent evaluation of the quality of evidence within the reviews presented. Finally, 
because the authors relied on past literature syntheses as their source of evidence, any publications not included in those reviews, such as newer trials or those that were not identified in the past systematic reviews, are not taken into account in the findings of this evidence map. While this mapping approach does capture the evidence across the various conditions and massage types in a broad sense, any detailed analysis of a particular condition or massage type should include an update search within that more focused scope to answer questions related to efficacy or effect.

The evidence mapping process can also inform future research priorities. When multiple systematic reviews within the evidence map overlap in pain indications, cross-checking of these reviews may be necessary to determine if the same primary studies are being described, the extent of the overlap, and applicability of some or all findings in a review for a particular research or policy question. For example, the four fibromyalgia systematic reviews had differing findings, with one each in the no difference, unclear mixed results, and potentially better categories. While there are some studies that overlap between these systematic reviews, there are also unique primary studies, with each review drawing conclusions from different sets of data. A future synthesis could compile studies included in all four reviews and develop new findings inclusive of all potential evidence. In addition, the topics with multiple bubbles, especially with differing findings, may be areas that are ripe for an updated systematic review. Other areas where future synthesis efforts would be beneficial include updating pain indications for which existing reviews are outdated (e.g., critical care). Date of publication and quality of review are also important considerations, especially when multiple systematic reviews have been conducted in the same topic area. As the evidence base grows, newer publications may have a larger amount of evidence to draw from, but newer reviews can also be of lower quality, and reviews identified during this mapping process varied in quality across time. In these cases, older higher quality syntheses offer more robust findings.

Learning from past research through evidence synthesis in a broad area such as massage for pain can require an iterative and tailored approach. Different audiences will be interested in parsing out the evidence most relevant to their needs and interests, and scopes will accordingly vary. Recently, a diverse set of stakeholders and subject matter experts were convened as the Evidence for Massage Therapy (EMT) Working Group to make recommendations about the use of massage for pain. ${ }^{66,67}$ The evidence synthesis work to support this group's recommendation process was broad, and the three resulting publications are of high quality and are included in their map. ${ }^{56,59,62}$ The EMT working group highlights the promise massage offers to help "overcome the current opioid-focused old thinking that has devastated many lives." 67 A separate effort to update the American College of Physicians Clinical Practice Guideline for nonpharmacologic therapies for low back pain included other synthesis work from multiple groups included in the current evidence map. ${ }^{26,32}$ This evidence map provides a broad overview that may serve as an entry point to better understand these various efforts.

\section{Conclusion}

Prior reviews have conclusions of low strength of evidence because few primary studies of large samples with rigorous methods had been conducted, leaving evidence gaps about specific massage type for specific pain indications. Primary studies often do not provide adequate details of massage therapy provided, limiting the extent to which reviews are able to draw conclusions about characteristics such as provider type.

\section{Acknowledgment}

This review is part of a larger review commissioned by the Department of Veterans Affairs, funded by the Veterans Affairs Quality Enhancement Research Initiative.

\section{Author Disclosure Statement}

No competing financial interests exist.

\section{Supplementary Material}

Supplementary Table S1

Supplementary Data

\section{References}

1. Relieving pain in America: A blueprint for transforming prevention, care, education, and research. Mil Med 2016; 181:397-399.

2. Nahin RL, Boineau R, Khalsa PS, et al. Evidence-based evaluation of complementary health approaches for pain management in the United States. Mayo Clin Proc 2016;91: 1292-1306.

3. National Center for Health Statistics. National Ambulatory Medical Care Survey: 2013 State and National Summary Tables. Hyattsville, MD: Public Health Service, 2016.

4. Turk DC, Wilson HD, Cahana A. Treatment of chronic non-cancer pain. Lancet 2011;377:2226-2235.

5. Cherkin DC, Sherman KJ, Deyo RA, Shekelle PG. A review of the evidence for the effectiveness, safety, and cost of acupuncture, massage therapy, and spinal manipulation for back pain. Ann Intern Med 2003;138:898-906.

6. Ernst E. The safety of massage therapy. Rheumatology (Oxford) 2003;42:1101-1106.

7. National Center for Complementary and Integrative Health (NCCIH). Massage therapy for health purposes. Online document at: https://nccih.nih.gov/health/massage/massage introduction.htm, accessed July 19, 2016.

8. Piper S, Shearer HM, Cote P, et al. The effectiveness of soft-tissue therapy for the management of musculoskeletal disorders and injuries of the upper and lower extremities: A systematic review by the Ontario Protocol for Traffic Injury management (OPTIMa) collaboration. Man Ther 2016;21: $18-34$.

9. Wilkinson S, Barnes K, Storey L. Massage for symptom relief in patients with cancer: Systematic review. J Adv Nurs 2008;63:430-439.

10. Bervoets DC, Luijsterburg PA, Alessie JJ, et al. Massage therapy has short-term benefits for people with common musculoskeletal disorders compared to no treatment: A systematic review. J Physiother 2015;61:106-116.

11. Yuan SL, Matsutani LA, Marques AP. Effectiveness of different styles of massage therapy in fibromyalgia: A systematic review and meta-analysis. Man Ther 2015;20:257-264.

12. American Massage Therapy Association. Types of massage. Online document at: www.amtamassage.org/findamassage/ massage_type.html, accessed July 14, 2016. 
13. National Certification Board for Therapeutic Massage \& Bodywork (NCBTMB). Glossary: Therapy and techniques. Online document at: www.ncbtmb.org/consumers/glossarytherapy-techniques, accessed July 14, 2016.

14. Furlan AD, Yazdi F, Tsertsvadze A, et al. Complementary and alternative therapies for back pain II. Evid Rep Technol Assess (Full Rep) 2010:1-764.

15. Brosseau L, Wells GA, Poitras S, et al. Ottawa panel evidence-based clinical practice guidelines on therapeutic massage for low back pain. J Bodyw Mov Ther 2012;16: 424-455.

16. Brosseau L, Wells GA, Tugwell P, et al. Ottawa panel evidence-based clinical practice guidelines on therapeutic massage for neck pain. J Bodyw Mov Ther 2012;16:300-325.

17. Ernst E, Pittler MH, Wider B, Boddy K. The Desktop Guide to Complementary and Alternative Medicine. 2nd ed. Edinburgh: Mosby Elsevier, 2006.

18. Furlan AD, Brosseau L, Imamura M, Irvin E. Massage for low-back pain: A systematic review within the framework of the Cochrane Collaboration Back Review Group. Spine 2002;27:1896-1910.

19. Miake-Lye IM, Hempel S, Shanman R, Shekelle PG. What is an evidence map? A systematic review of published evidence maps and their definitions, methods, and products. Syst Rev 2016;5:1.

20. Moher D, Shamseer L, Clarke M, et al. Preferred reporting items for systematic review and meta-analysis protocols (PRISMA-P) 2015 statement. Syst Rev 2015;4:1.

21. Miake-Lye IM, Lee JF, Luger T, et al. Massage for Pain: An Evidence Map. Washington, DC: Evidence Synthesis Program, Health Services Research and Development Service, Office of Research and Development, Department of Veterans Affairs. VA ESP Project \#05-226; 2016. Available at: https://www.hsrd.research.va.gov/publications/esp/ reports.cfm.

22. Shea BJ, Grimshaw JM, Wells GA, et al. Development of AMSTAR: A measurement tool to assess the methodological quality of systematic reviews. BMC Med Res Methodol 2007;7:1.

23. Balshem H, Helfand M, Schünemann HJ, et al. GRADE guidelines: 3. Rating the quality of evidence. J Clin Epidemiol 2011;64:401-406.

24. Ballard M, Montgomery P. Risk of bias in overviews of reviews: A scoping review of methodological guidance and four-item checklist. Res Synth Methods 2017;8:92-108.

25. Furlan AD, Brosseau L, Imamura M, Irvin E. Massage for low back pain. Cochrane Database Syst Rev 2002;4: CD001929.

26. Furlan AD, Imamura M, Dryden T, Irvin E. Massage for low-back pain. Cochrane Database Syst Rev 2008;4: CD001929.

27. Furlan AD, Imamura M, Dryden T, Irvin E. Massage for low back pain: An updated systematic review within the framework of the Cochrane Back Review Group. Spine 2009;34:1669-1684.

28. Furlan AD, Yazdi F, Tsertsvadze A, et al. A systematic review and meta-analysis of efficacy, cost-effectiveness, and safety of selected complementary and alternative medicine for neck and low-back pain. Evid Based Complement Alternat Med 2012;2012:953139.

29. Terhorst L, Schneider MJ, Kim KH, et al. Complementary and alternative medicine in the treatment of pain in fibromyalgia: A systematic review of randomized controlled trials. J Manipulative Physiol Ther 2011;34:483-496.
30. Smith CA, Levett KM, Collins CT, Jones L. Massage, reflexology and other manual methods for pain management in labour. Cochrane Database Syst Rev 2012;2: CD009290.

31. Smith CA, Collins CT, Cyna AM, Crowther CA. Complementary and alternative therapies for pain management in labour. Cochrane Database Syst Rev 2006;4:CD003521.

32. Chou R, Deyo R, Friedly J, et al. Nonpharmacologic therapies for low back pain: A systematic review for an American College of Physicians clinical practice guideline. Ann Intern Med 2017;166:493-505.

33. Lin YC, Wan L, Jamison RN. Using integrative medicine in pain management: An evaluation of current evidence. Anesth Analg 2017;125:2081-2093.

34. Bardia A, Barton DL, Prokop LJ, et al. Efficacy of complementary and alternative medicine therapies in relieving cancer pain: A systematic review. J Clin Oncol 2006;24: 5457-5464.

35. Huntley AL, Coon JT, Ernst E. Complementary and alternative medicine for labor pain: A systematic review. Am J Obstet Gynecol 2004;191:36-44.

36. Pan CX, Morrison RS, Ness J, et al. Complementary and alternative medicine in the management of pain, dyspnea, and nausea and vomiting near the end of life. A systematic review. J Pain Symptom Manage 2000;20:374-387.

37. van den Dolder PA, Ferreira PH, Refshauge KM. Effectiveness of soft tissue massage and exercise for the treatment of non-specific shoulder pain: A systematic review with meta-analysis. Br J Sports Med 2014;48:1216-1226.

38. Chou R, Deyo R, Friedly J, et al. AHRQ Comparative Effectiveness Reviews: Noninvasive Treatments for Low Back Pain. Rockville, MD: Agency for Healthcare Research and Quality (U.S.), 2016.

39. Shin ES, Seo KH, Lee SH, et al. Massage with or without aromatherapy for symptom relief in people with cancer. Cochrane Database Syst Rev 2016;6:CD009873.

40. Anthonissen M, Daly D, Janssens T, Van den Kerckhove E. The effects of conservative treatments on burn scars: A systematic review. Burns 2016;42:508-518.

41. Sut N, Kahyaoglu-Sut H. Effect of aromatherapy massage on pain in primary dysmenorrhea: A meta-analysis. Complement Ther Clin Pract 2017;27:5-10.

42. Chen TH, Tung TH, Chen PS, et al. The clinical effects of aromatherapy massage on reducing pain for the cancer patients: Meta-analysis of randomized controlled trials. Evid Based Complement Alternat Med 2016;2016:9147974.

43. Keeratitanont K, Jensen MP, Chatchawan U, Auvichayapat P. The efficacy of traditional Thai massage for the treatment of chronic pain: A systematic review. Complement Ther Clin Pract 2015;21:26-32.

44. Barreto DM, Batista MVA. Swedish massage: A systematic review of its physical and psychological benefits. Adv Mind Body Med 2017;31:16-20.

45. Wei X, Wang S, Li L, Zhu L. Clinical evidence of chinese massage therapy (Tui $\mathrm{Na}$ ) for cervical radiculopathy: A systematic review and meta-analysis. Evid Based Complement Alternat Med 2017;2017:9519285.

46. Loew LM, Brosseau L, Tugwell P, et al. Deep transverse friction massage for treating lateral elbow or lateral knee tendinitis. Cochrane Database Syst Rev 2014;11: CD003528.

47. Kong L, Bannuru RR, Yuan W, et al. Therapeutic massage on pain relief for fibromyalgia: A systematic review and meta-analysis. Arthritis Rheum 2011;63:2011. 
48. Lewis M, Johnson MI. The clinical effectiveness of therapeutic massage for musculoskeletal pain: A systematic review. Physiotherapy 2006;92:146-158.

49. Haraldsson BG, Gross AR, Myers CD, et al. Massage for mechanical neck disorders. Cochrane Database Syst Rev 2006;3:CD004871.

50. Ezzo J, Haraldsson BG, Gross AR, et al. Massage for mechanical neck disorders: A systematic review. Spine 2007;32:353-362.

51. Miozzo AP, Stein C, Bozzetto CB, Plentz RDM. Massage therapy reduces pain and anxiety after cardiac surgery: A systematic review and meta-analysis of randomized clinical trials. Clin Trials Regul Sci Cardiol 2016;23-24:1-8.

52. Lee SH, Kim JY, Yeo S, et al. Meta-analysis of massage therapy on cancer pain. Integr Cancer Ther 2015;14:297304.

53. Guo J, Li L, Gong Y, et al. Massage alleviates delayed onset muscle soreness after strenuous exercise: A systematic review and meta-analysis. Front Physiol 2017;8: 747.

54. Boitor M, Gelinas C, Richard-Lalonde M, Thombs BD. The effect of massage on acute postoperative pain in critically and acutely ill adults post-thoracic surgery: Systematic review and meta-analysis of randomized controlled trials. Heart Lung 2017;46:339-346.

55. Smith CA, Levett KM, Collins CT, et al. Massage, reflexology and other manual methods for pain management in labour. Cochrane Database Syst Rev 2018;3: CD009290.

56. Crawford C, Boyd C, Paat CF, et al. The impact of massage therapy on function in pain populations-A systematic review and meta-analysis of randomized controlled trials: Part I, patients experiencing pain in the general population. Pain Med 2016;17:1353-1375.

57. Furlan AD, Giraldo M, Baskwill A, et al. Massage for lowback pain. Cochrane Database Syst Rev 2015;9:CD001929.

58. Nelson NL, Churilla JR. Massage therapy for pain and function in patients with arthritis: A systematic review of randomized controlled trials. Am J Phys Med Rehabil 2017;96:665-672.

59. Boyd C, Crawford C, Paat CF, et al. The impact of massage therapy on function in pain populations-A systematic review and meta-analysis of randomized controlled trials: Part II, cancer pain populations. Pain Med 2016;17:15531568.

60. Ault P, Plaza A, Paratz J. Scar massage for hypertrophic burns scarring-A systematic review. Burns 2018;44:24-38.

61. Patel KC, Gross A, Graham N, et al. Massage for mechanical neck disorders. Cochrane Database Syst Rev 2012; 9:CD004871.

62. Boyd C, Crawford C, Paat CF, et al. The impact of massage therapy on function in pain populations-A systematic review and meta-analysis of randomized controlled trials: Part III, surgical pain populations. Pain Med 2016;17: 1757-1772.
63. Kong LJ, Zhan HS, Cheng YW, et al. Massage therapy for neck and shoulder pain: A systematic review and metaanalysis. Evid Based Complement Alternat Med 2013; 2013:613279.

64. Calixtre LB, Moreira RF, Franchini GH, et al. Manual therapy for the management of pain and limited range of motion in subjects with signs and symptoms of temporomandibular disorder: A systematic review of randomised controlled trials. J Oral Rehabil 2015;42:847-861.

65. Li YH, Wang FY, Feng CQ, et al. Massage therapy for fibromyalgia: A systematic review and meta-analysis of randomized controlled trials. PloS One 2014;9:e89304.

66. Jonas W, Schoomaker E, Berry K, Buckenmaier C, 3rd. A time for massage. Pain Med 2016;17:1389-1390.

67. Buckenmaier C, Cambron J, Werner R, et al. Massage therapy for pain-call to action. Pain Med 2016;17:1211.

68. Cheng YH, Huang GC. Efficacy of massage therapy on pain and dysfunction in patients with neck pain: A systematic review and meta-analysis. Evid Based Complement Alternat Med 2014;2014:204360.

69. Kukimoto Y, Ooe N, Ideguchi N. The effects of massage therapy on pain and anxiety after surgery: A systematic review and meta-analysis. Pain Manag Nurs 2017;18:378390.

70. Lee PL, Tam KW, Yeh ML, Wu WW. Acupoint stimulation, massage therapy and expressive writing for breast cancer: A systematic review and meta-analysis of randomized controlled trials. Complement Ther Med 2016;27:87-101.

71. Yeun YR. Effectiveness of massage therapy for shoulder pain: A systematic review and meta-analysis. J Phys Ther Sci 2017;29:936-940.

72. Ernst E. Massage therapy for cancer palliation and supportive care: A systematic review of randomised clinical trials. Support Care Cancer 2009;17:333-337.

73. Ranjbaran M, Khorsandi M, Matourypour P, Shamsi M. Effect of massage therapy on labor pain reduction in primiparous women: A systematic review and meta-analysis of randomized controlled clinical trials in Iran. Iran J Nurs Midwifery Res 2017;22:257-261.

74. Ajimsha MS, Al-Mudahka NR, Al-Madzhar JA. Effectiveness of myofascial release: Systematic review of randomized controlled trials. J Bodyw Mov Ther 2015;19:102-112.

75. Ernst E. Massage therapy for low back pain: A systematic review. J Pain Symptom Manage 1999;17:65-69.

76. Richards KC, Gibson R, Overton-McCoy AL. Effects of massage in acute and critical care. AACN Clin Issues 2000; 11:77-96.

Address correspondence to: Isomi Miake-Lye, PhD

West Los Angeles Veterans Affairs Medical Center 11301 Wilshire Boulevard, Building 206 Los Angeles, CA 90073

E-mail: isomi.miake-lye@va.gov 


\section{Appendix 1. Criteria Used in Quality Assessment}

Modified AMSTAR - a measurement tool to assess the methodological quality of systematic reviews.

NOTE: where alterations were made to original AMSTAR criteria, language is bolded. Removal of original criteria is displayed with a strikethrough, and additions are displayed in italics.

1. Was an "a priori" design provided?

The research question and inclusion criteria should be established before the conduct of the review.

Note: Need to refer to a protocol, ethics approval, or predetermined/a priori published research objectives to score a "yes."

Yes/ No/ Can't answer/ Not applicable

2. Was there duplicate study selection and data extraction?

There should be at least two independent data extractors, and a consensus procedure for disagreements should be in place.

Note: 2 people do study selection, 2 people do data extraction, consensus process, or one person checks the other's work.

Yes/ No/ Can't answer/ Not applicable

3. Was a comprehensive literature search performed?

At least two electronic sources should be searched. The report must include years and databases used (e.g., Central, EMBASE, and MEDLINE). Key words and/or MESH terms must be stated and where feasible the search strategy should be provided. All searches should be supplemented by consulting current contents, reviews, textbooks, specialized registers, or experts in the particular field of study, and by reviewing the references in the studies found.

Note: If at least 2 sources + one supplementary strategy used, select "yes" (Cochrane register/Central counts as 2 sources; a gray literature search counts as supplementary).

Yes/ No/ Can't answer/ Not applicable

4. Was the status of publication (i.e. gray literature) used as an inclusion criterion?

The authors should state that they searched for reports regardless of their publication type. The authors should state whether or not they excluded any reports (from the systematic review), based on their publication status, language etc. Note: If review indicates that there was a search for "gray literature" or "unpublished literature," indicate "yes." SIGLE database, dissertations, conference proceedings, and trial registries are all considered gray for this purpose. If searching a source that contains both gray and nongray, must specify that they were searching for gray/unpublished lit. Yes/ No/ Can't answer/ Not applicable

5. Was a list of studies (included and exeltted) provided?

A list of included and-exeluted studies should be provided.

Note: Acceptable if the excluded studies are referenced. If there is an electronic link to the list but the link is dead, select "no."

Yes/ No/ Can't answer/ Not applicable

6. Were the characteristics of the included studies provided?

In an aggregated form such as a table, data from the original studies should be provided on the participants, interventions, and outcomes. The ranges of characteristics in all the studies analyzed, e.g., age, race, sex, relevant socioeconomic data, disease status, duration, severity, or other diseases, should be reported.

Note: Acceptable if not in table format as long as they are described as above.

Yes/ No/ Can't answer/ Not applicable

7. Was the scientific quality of the included studies assessed and documented?

"A priori" methods of assessment should be provided (e.g., for effectiveness studies if the author(s) chose to include only randomized, double-blind, placebo controlled studies, or allocation concealment as inclusion criteria); for other types of studies alternative items will be relevant.

Note: Can include use of a quality scoring tool or checklist, e.g., Jadad scale, risk of bias, sensitivity analysis, etc., or a description of quality items, with some kind of result for EACH study ("low" or "high" is fine, as long as it is clear which studies scored "low" and which scored "high"; a summary score/range for all studies is not acceptable).

Yes/ No/ Can't answer/ Not applicable

8. Was the scientific quality of the included studies used appropriately in formulating conclusions?

The results of the methodological rigor and scientific quality should be considered in the analysis and the conclusions of the review and explicitly stated in formulating recommendations.

Note: Might say something such as "the results should be interpreted with caution due to poor quality of included studies." Cannot score "yes" for this question if scored "no" for question 7.

Yes/ No/ Can't answer/ Not applicable

9. Were the methods used to combine the findings of studies appropriate?

For the pooled results, a test should be done to ensure the studies were combinable, to assess their homogeneity (i.e., Chi-squared test for homogeneity, I2). If heterogeneity exists a random effects model should be used and/or the clinical appropriateness of combining should be taken into consideration (i.e., is it sensible to combine?). 
Note: Indicate "yes" if they mention or describe heterogeneity, i.e., if they explain that they cannot pool because of heterogeneity/variability between interventions.

Yes/ No/ Can't answer/ Not applicable

10. Was the likelihood of publication bias assessed?

An assessment of publication bias should include a combination of graphical aids (e.g., funnel plot and other available tests) and/or statistical tests (e.g., Egger regression test and Hedges-Olken).

Note: If no test values or funnel plot included, score "no". Score "yes" if it mentions that publication bias could not be assessed because there were fewer than 10 included studies.

For strictly narrative systematic reviews (i.e., no quantitative methods employed), some narrative discussion of publication bias is required to score yes.

Yes/ No/ Can't answer/ Not applicable

11. Was the conflict of interest included?

Potential sources of support should be clearly acknowledged in both the systematic review and the ineludedstudies. Note: To get a "yes," must indicate source of funding or support for the systematic wew AND for each of the included studies.

Yes/ No/ Can't answer/ Not applicable

Original source: Shea BJ, Grimshaw JM, Wells GA, et al. Development of AMSTAR: A measurement tool to assess the methodological quality of systematic reviews. BMC Med Res Methodol 2007;7:1. 


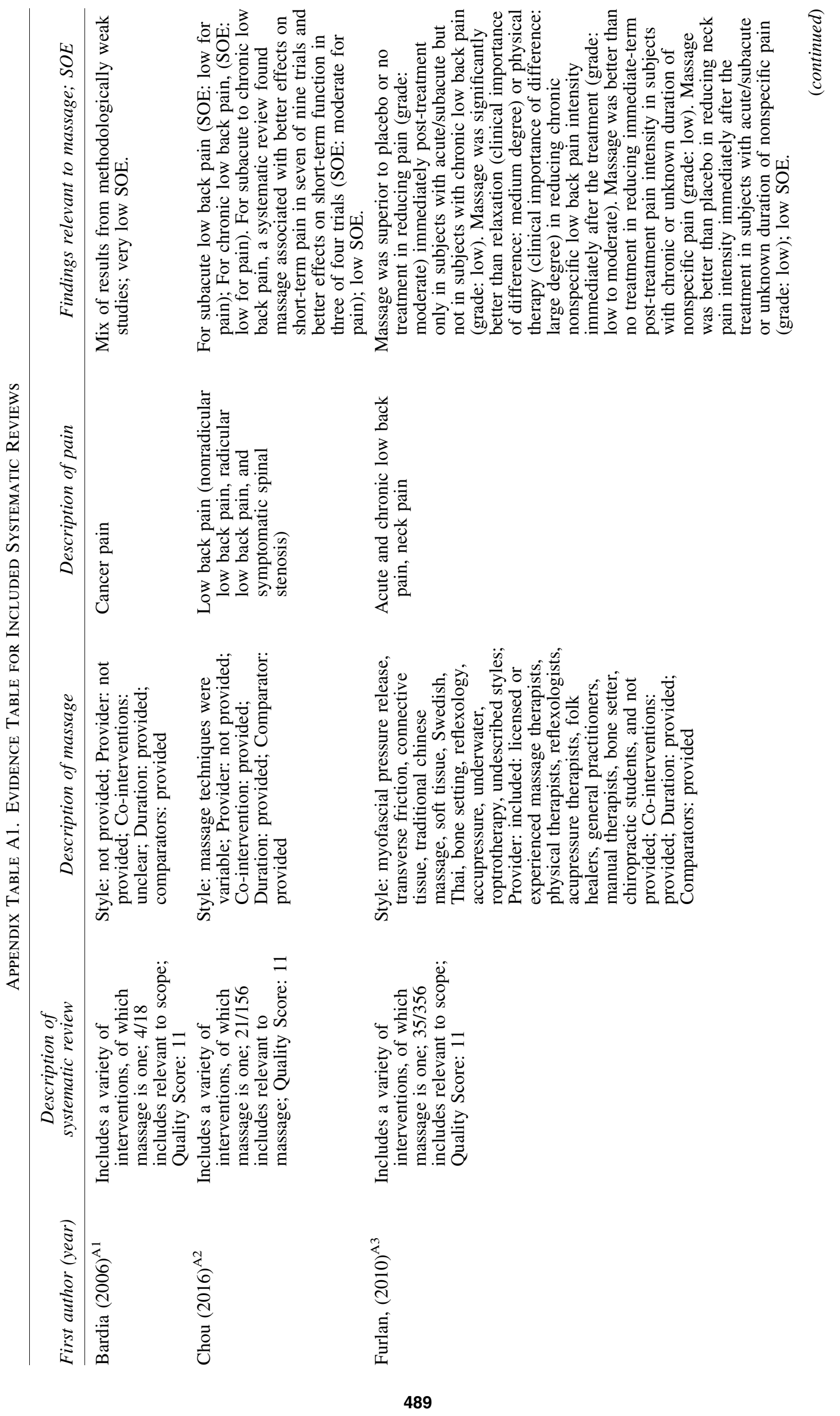




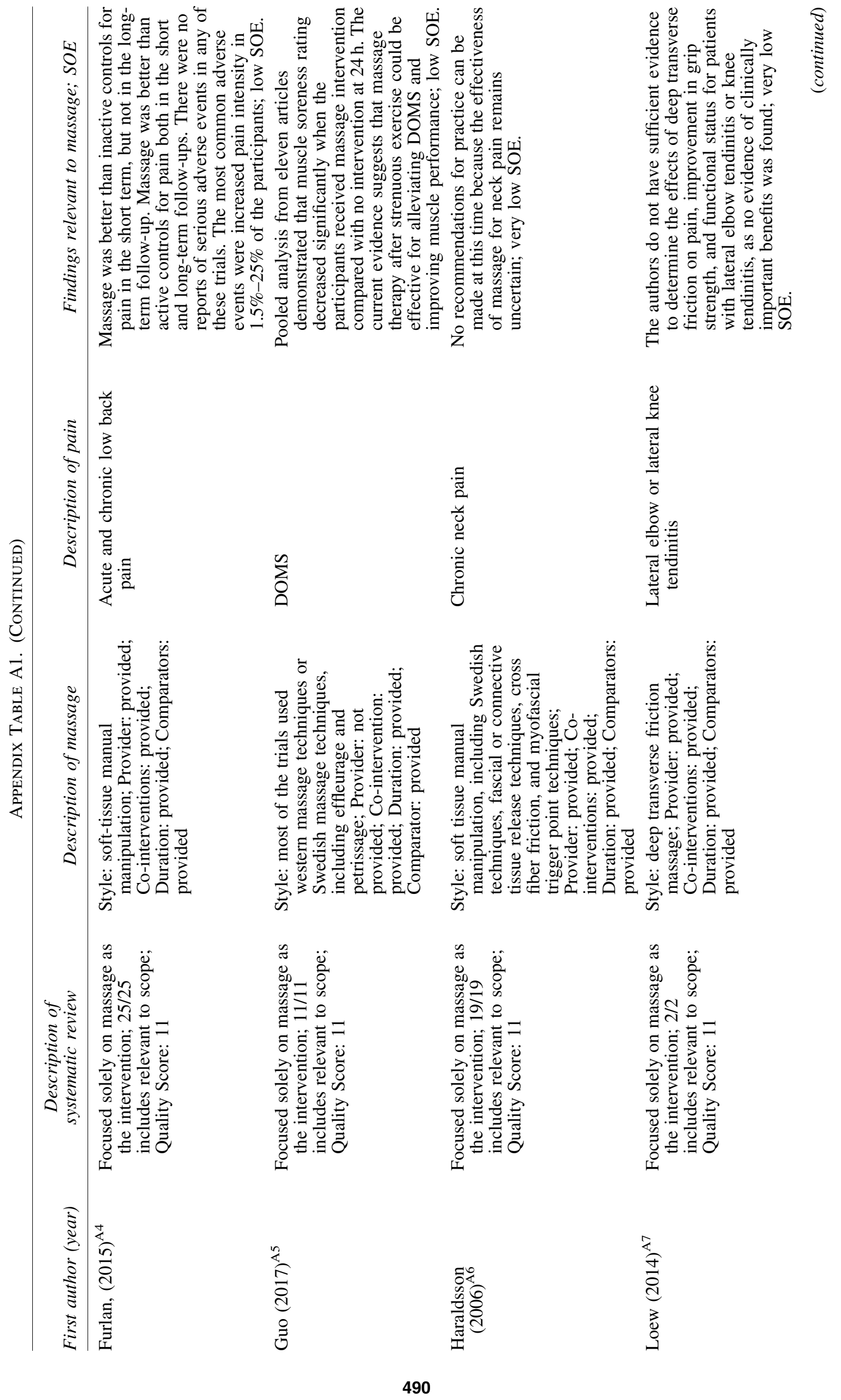




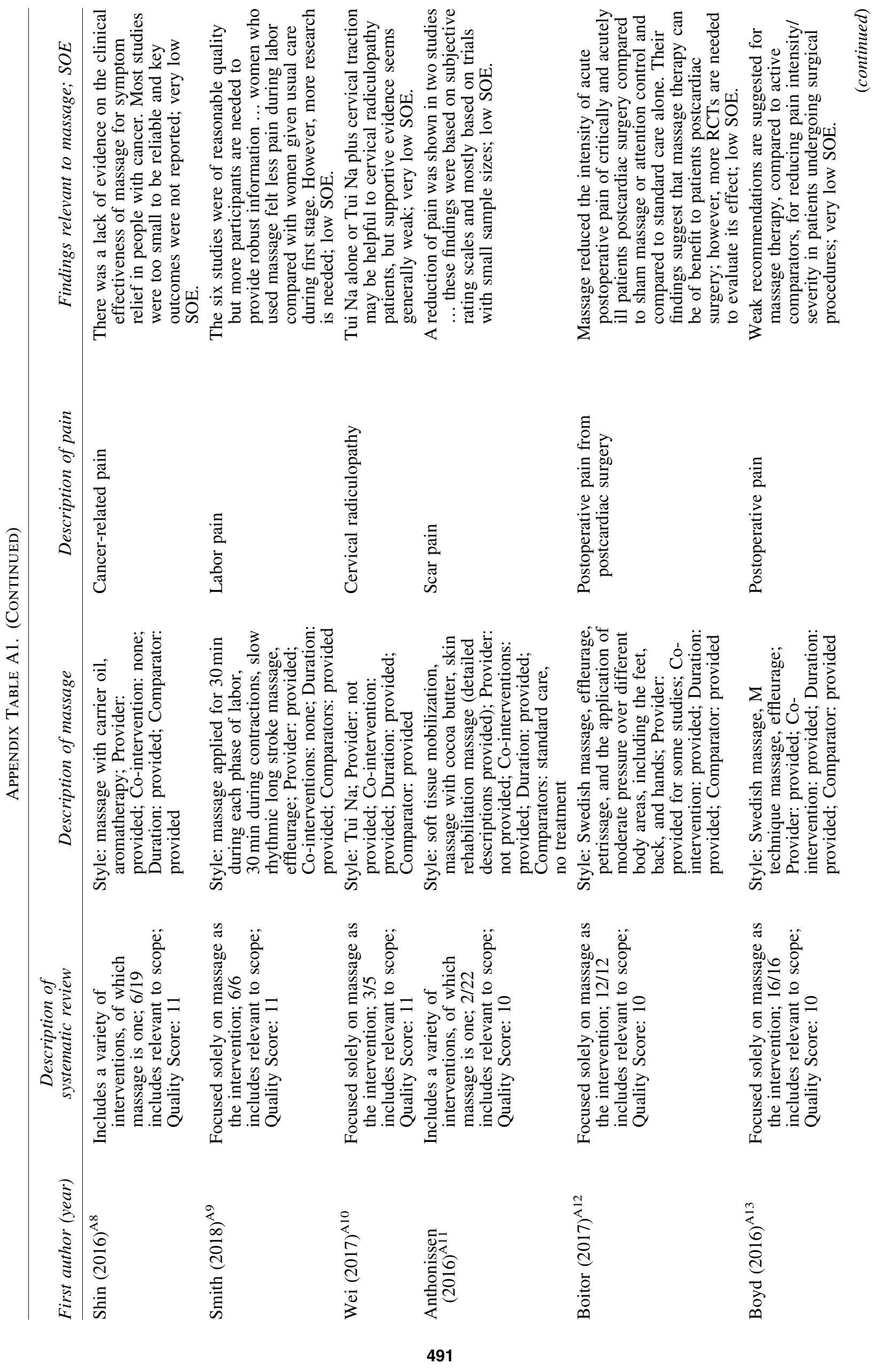




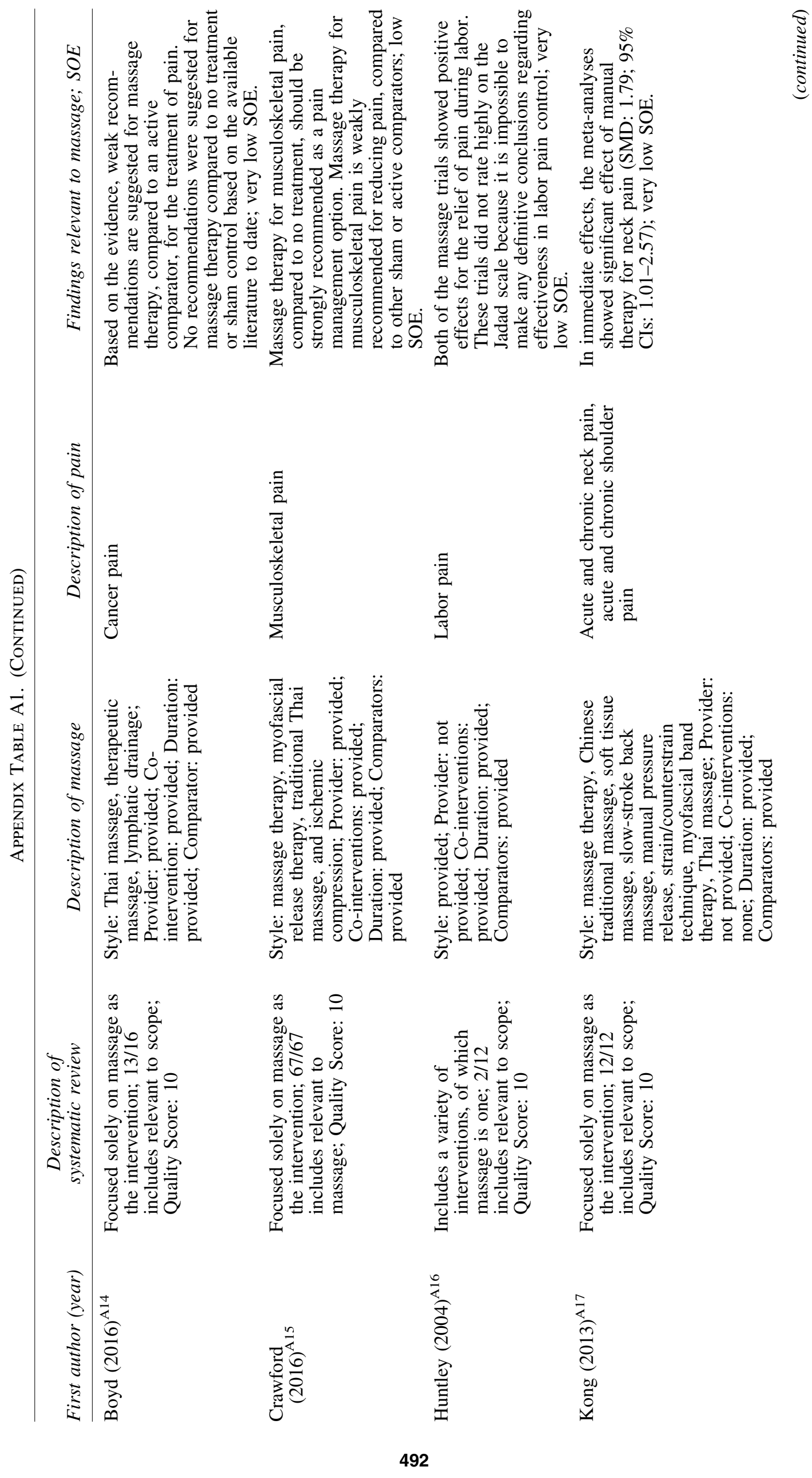




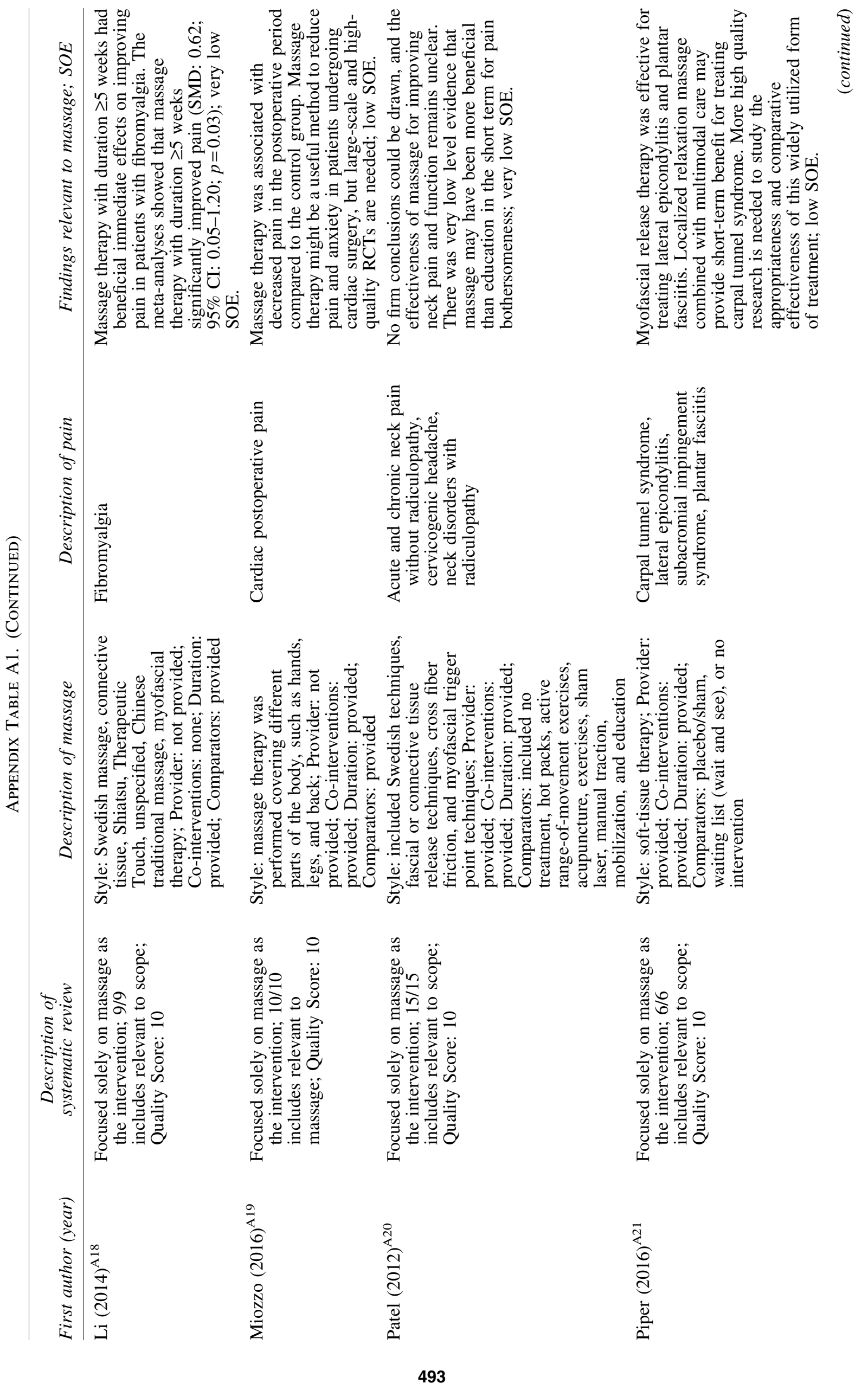




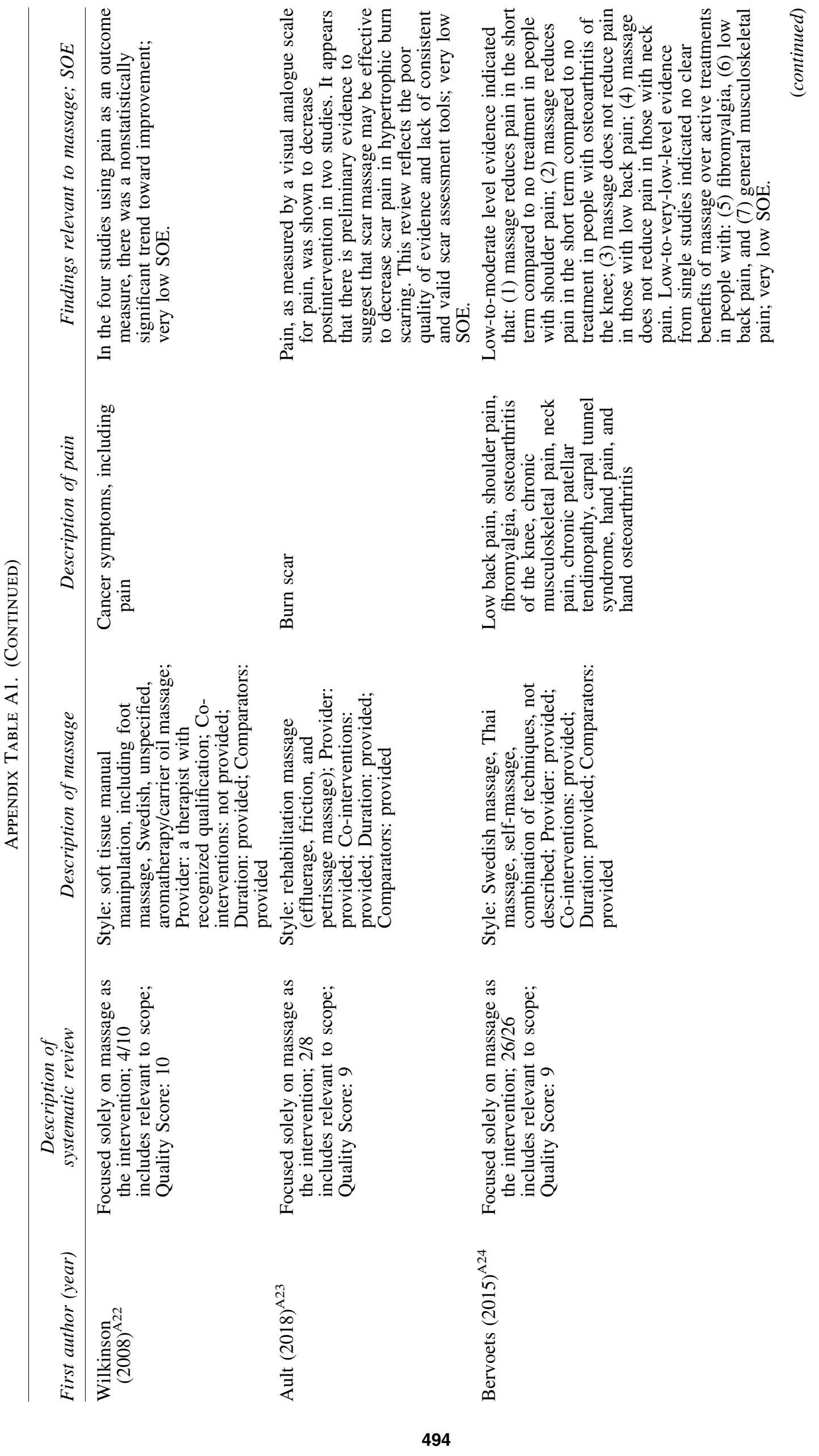




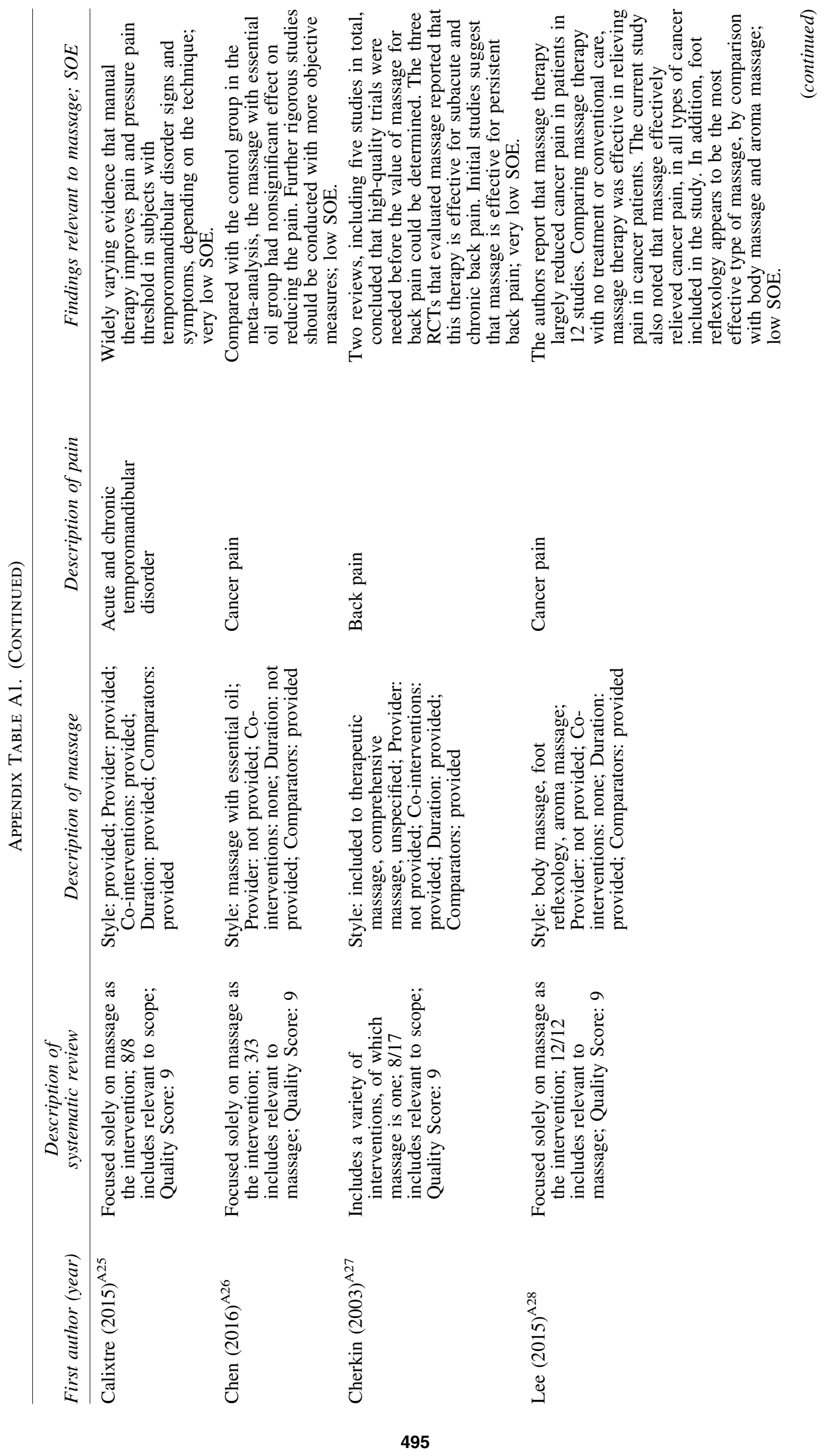




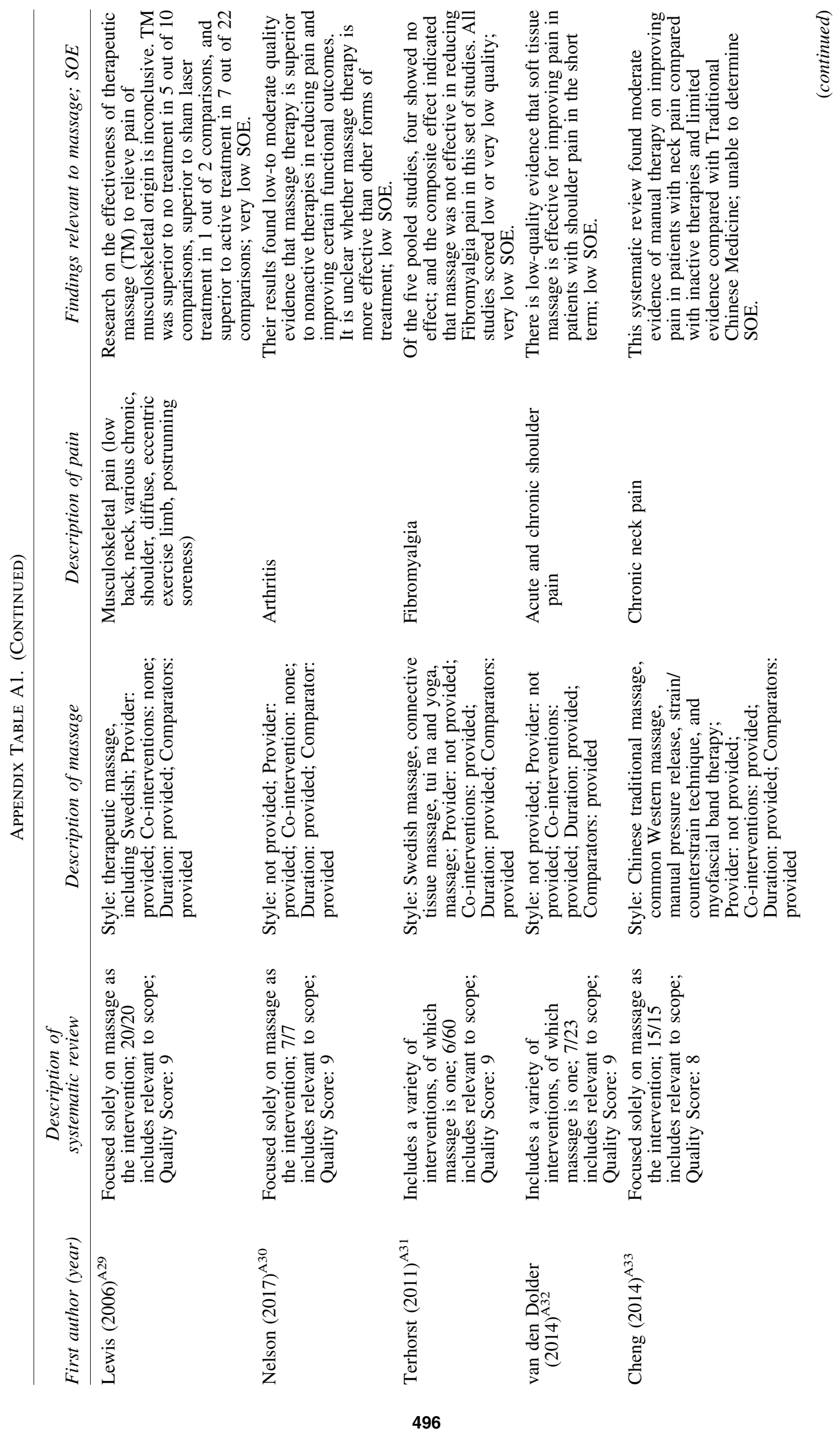




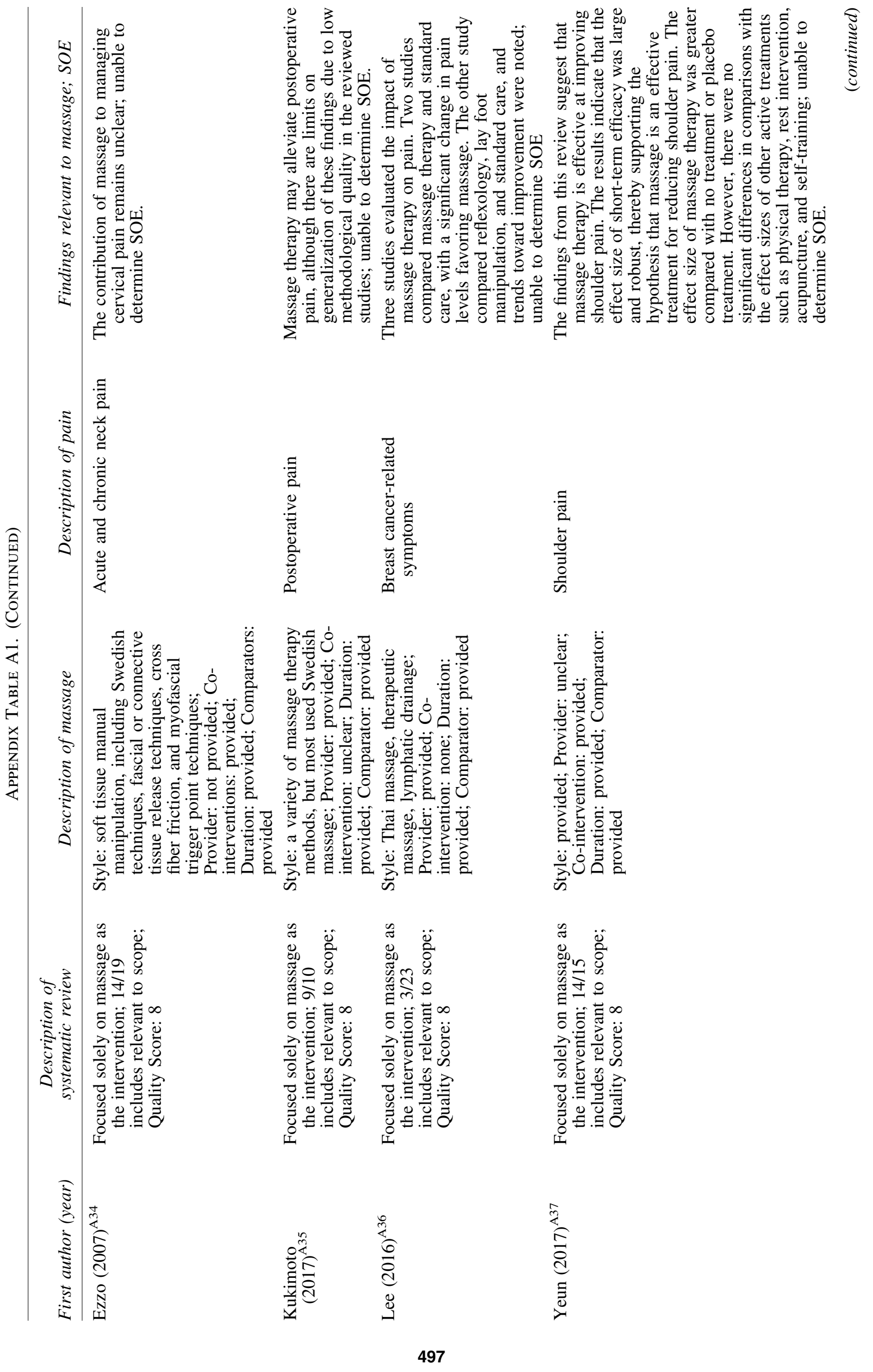




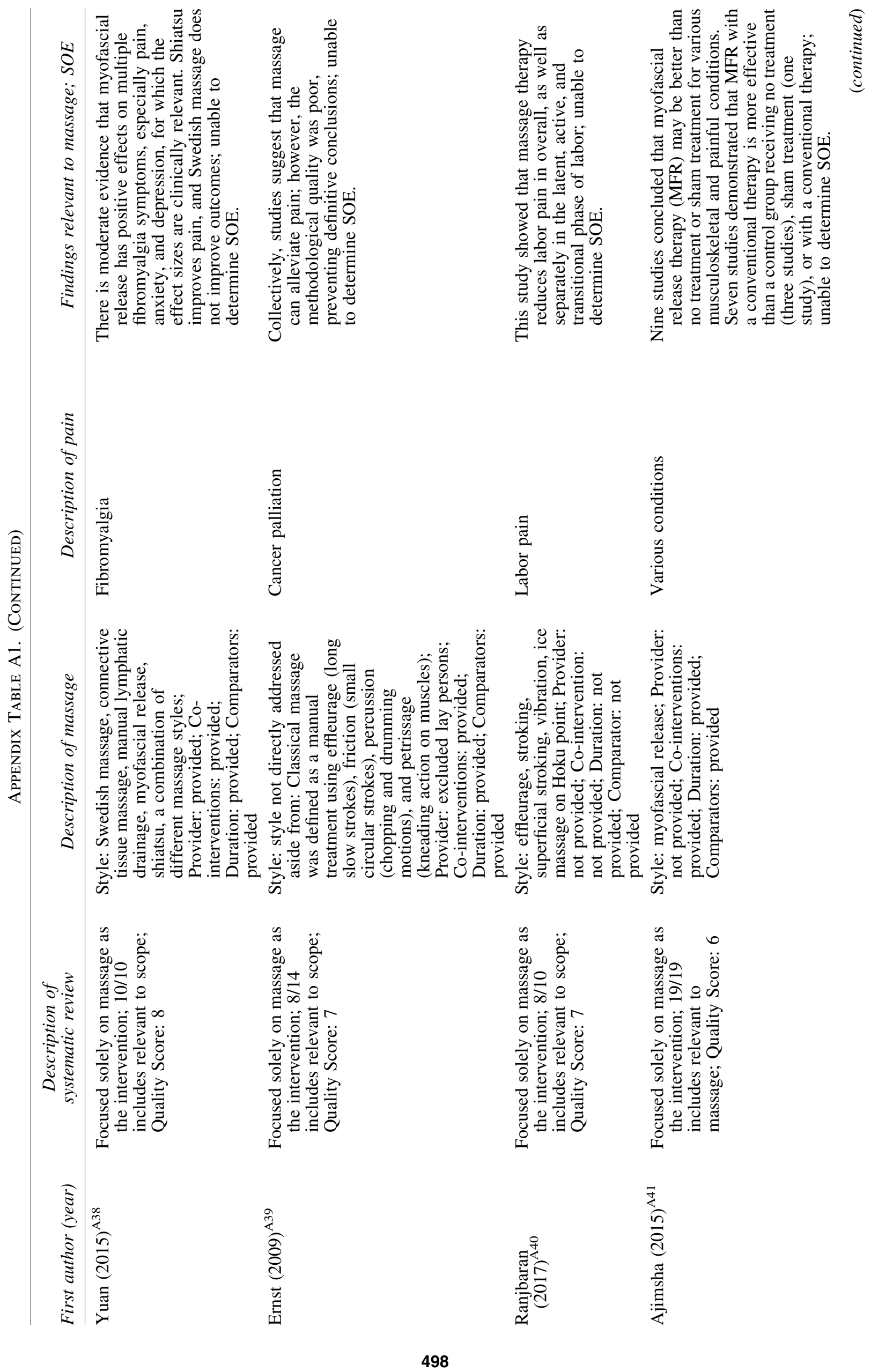




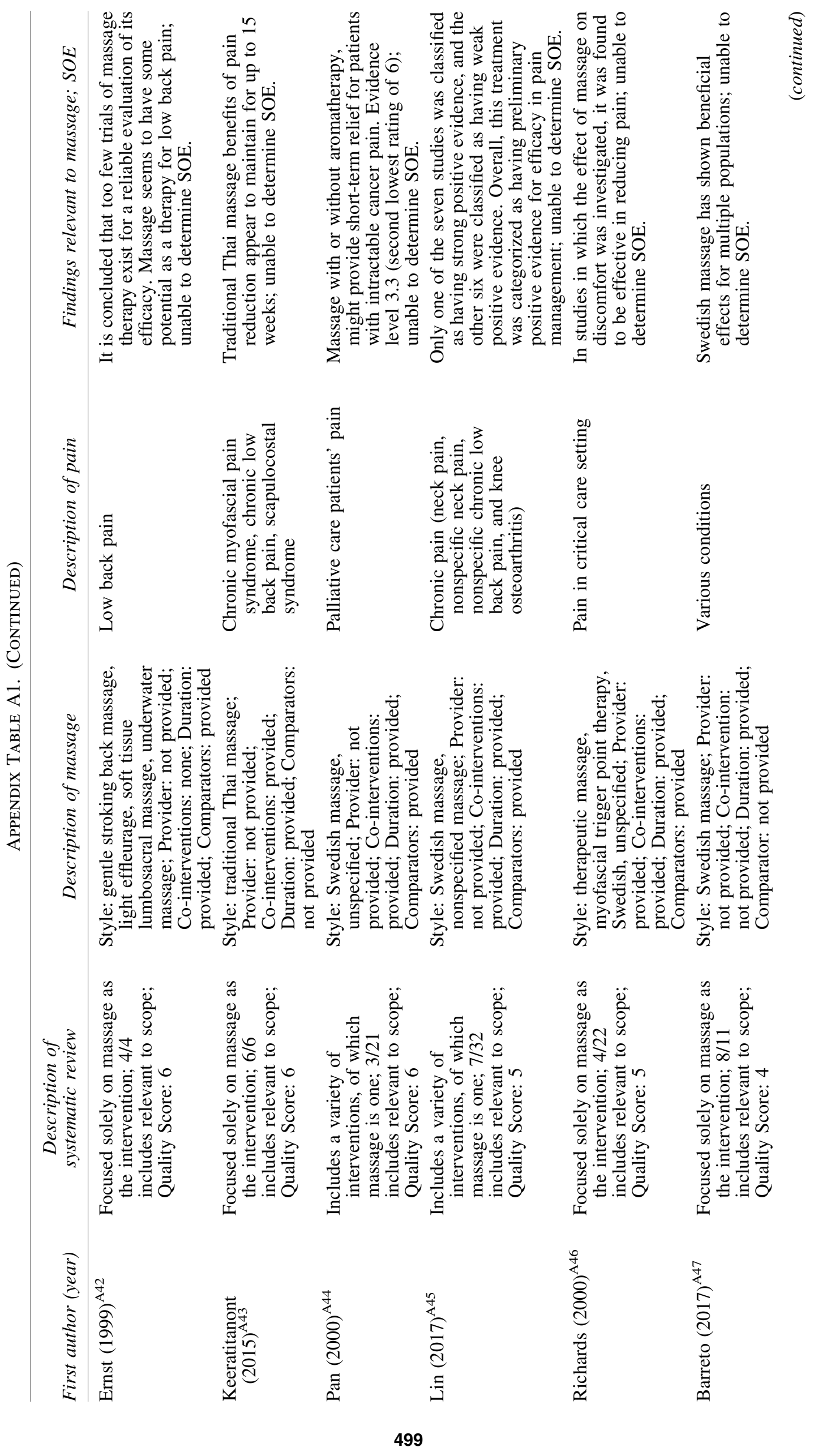




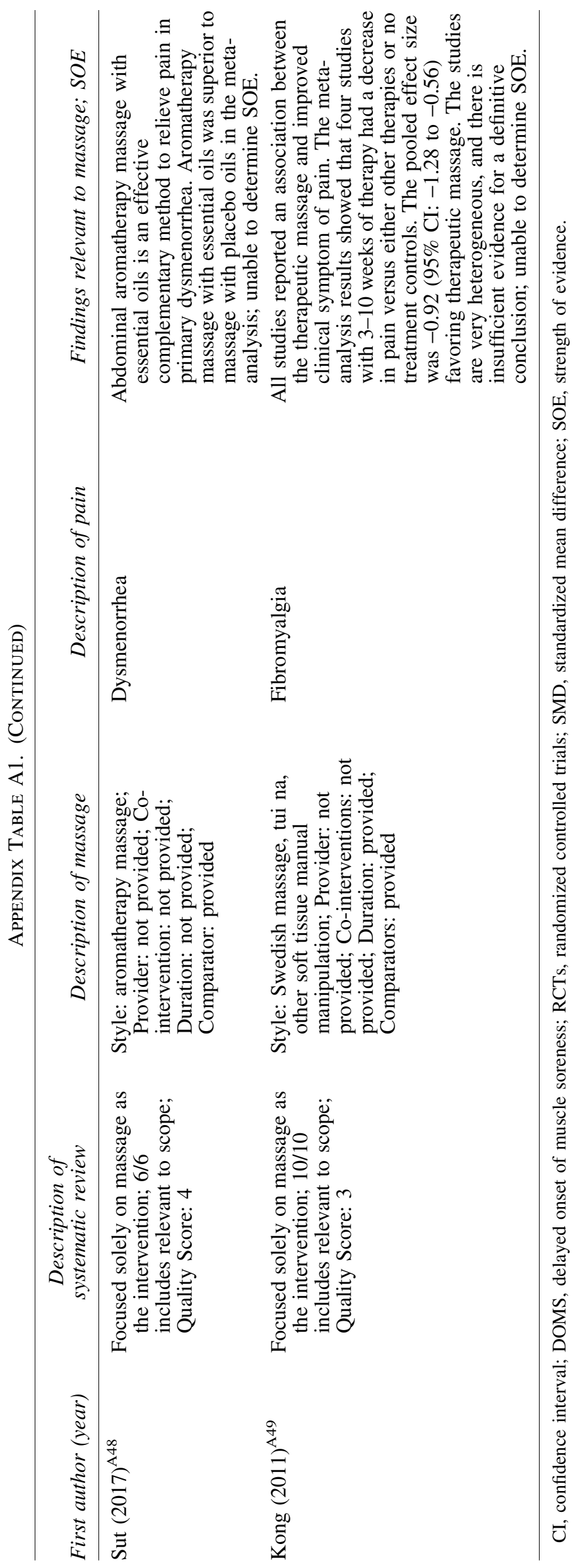




\section{Appendix References}

A1. Bardia A, Barton DL, Prokop LJ, et al. Efficacy of complementary and alternative medicine therapies in relieving cancer pain: A systematic review. J Clin Oncol 2006;24:5457-5464.

A2. Chou R, Deyo R, Friedly J, et al. AHRQ Comparative Effectiveness Reviews: Noninvasive Treatments for Low Back Pain. Rockville, MD: Agency for Healthcare Research and Quality (U.S.), 2016.

A3. Furlan AD, Yazdi F, Tsertsvadze A, et al. Complementary and alternative therapies for back pain II. Evid Rep Technol Assess (Full Rep) 2010:1-764.

A4. Furlan AD, Giraldo M, Baskwill A, et al. Massage for low-back pain. Cochrane Database Syst Rev 2015;9:CD001929.

A5. Guo J, Li L, Gong Y, et al. Massage alleviates delayed onset muscle soreness after strenuous exercise: A systematic review and meta-analysis. Front Physiol 2017;8:747.

A6. Haraldsson BG, Gross AR, Myers CD, et al. Massage for mechanical neck disorders. Cochrane Database Syst Rev 2006;3: CD004871.

A7. Loew LM, Brosseau L, Tugwell P, et al. Deep transverse friction massage for treating lateral elbow or lateral knee tendinitis. Cochrane Database Syst Rev 2014;11:CD003528.

A8. Shin ES, Seo KH, Lee SH, et al. Massage with or without aromatherapy for symptom relief in people with cancer. Cochrane Database Syst Rev 2016;6:CD009873.

A9. Smith CA, Levett KM, Collins CT, et al. Massage, reflexology and other manual methods for pain management in labour. Cochrane Database Syst Rev 2018;3:CD009290.

A10. Wei X, Wang S, Li L, Zhu L. Clinical evidence of chinese massage therapy (Tui Na) for cervical radiculopathy: A systematic review and meta-analysis. Evid Based Complement Alternat Med 2017;2017:9519285.

A11. Anthonissen M, Daly D, Janssens T, van den Kerckhove E. The effects of conservative treatments on burn scars: A systematic review. Burns 2016;42:508-518.

A12. Boitor M, Gelinas C, Richard-Lalonde M, Thombs BD. The effect of massage on acute postoperative pain in critically and acutely ill adults post-thoracic surgery: Systematic review and meta-analysis of randomized controlled trials. Heart Lung 2017;46:339-346.

A13. Boyd C, Crawford C, Paat CF, et al. The impact of massage therapy on function in pain populations-A systematic review and meta-analysis of randomized controlled trials: Part III, surgical pain populations. Pain Med 2016;17:1757-1772.

A14. Boyd C, Crawford C, Paat CF, et al. The impact of massage therapy on function in pain populations-A systematic review and meta-analysis of randomized controlled trials: Part II, cancer pain populations. Pain Med 2016;17:1553-1568.

A15. Crawford C, Boyd C, Paat CF, et al. The impact of massage therapy on function in pain populations-A systematic review and meta-analysis of randomized controlled trials: Part I, patients experiencing pain in the general population. Pain Med 2016;17:1353-1375.

A16. Huntley AL, Coon JT, Ernst E. Complementary and alternative medicine for labor pain: A systematic review. Am J Obstet Gynecol 2004;191:36-44.

A17. Kong LJ, Zhan HS, Cheng YW, et al. Massage therapy for neck and shoulder pain: A systematic review and meta-analysis. Evid Based Complement Alternat Med 2013;2013:613279.

A18. Li YH, Wang FY, Feng CQ, et al. Massage therapy for fibromyalgia: A systematic review and meta-analysis of randomized controlled trials. PloS One 2014;9:e89304.

A19. Miozzo AP, Stein C, Bozzetto CB, Plentz RDM. Massage therapy reduces pain and anxiety after cardiac surgery: A systematic review and meta-analysis of randomized clinical trials. Clin Trials Regul Sci Cardiol 2016;23-24:1-8.

A20. Patel KC, Gross A, Graham N, et al. Massage for mechanical neck disorders. Cochrane Database Syst Rev 2012;9: CD004871.

A21. Piper S, Shearer HM, Cote P, et al. The effectiveness of soft-tissue therapy for the management of musculoskeletal disorders and injuries of the upper and lower extremities: A systematic review by the Ontario Protocol for Traffic Injury management (OPTIMa) collaboration. Man Ther 2016;21:18-34.

A22. Wilkinson S, Barnes K, Storey L. Massage for symptom relief in patients with cancer: Systematic review. J Adv Nurs 2008; 63:430-439.

A23. Ault P, Plaza A, Paratz J. Scar massage for hypertrophic burns scarring-A systematic review. Burns 2018;44:24-38.

A24. Bervoets DC, Luijsterburg PA, Alessie JJ, et al. Massage therapy has short-term benefits for people with common musculoskeletal disorders compared to no treatment: A systematic review. J Physiother 2015;61:106-116.

A25. Calixtre LB, Moreira RF, Franchini GH, et al. Manual therapy for the management of pain and limited range of motion in subjects with signs and symptoms of temporomandibular disorder: A systematic review of randomised controlled trials. $\mathrm{J}$ Oral Rehabil 2015;42:847-861.

A26. Chen TH, Tung TH, Chen PS, et al. The clinical effects of aromatherapy massage on reducing pain for the cancer patients: Meta-analysis of randomized controlled trials. Evid Based Complement Alternat Med 2016;2016:9147974.

A27. Cherkin DC, Sherman KJ, Deyo RA, Shekelle PG. A review of the evidence for the effectiveness, safety, and cost of acupuncture, massage therapy, and spinal manipulation for back pain. Ann Intern Med 2003;138:898-906.

A28. Lee SH, Kim JY, Yeo S, et al. Meta-analysis of massage therapy on cancer pain. Integr Cancer Ther 2015;14:297-304.

A29. Lewis M, Johnson MI. The clinical effectiveness of therapeutic massage for musculoskeletal pain: A systematic review. Physiotherapy 2006;92:146-158.

A30. Nelson NL, Churilla JR. Massage therapy for pain and function in patients with arthritis: A systematic review of randomized controlled trials. Am J Phys Med Rehabil 2017;96:665-672.

A31. Terhorst L, Schneider MJ, Kim KH, et al. Complementary and alternative medicine in the treatment of pain in fibromyalgia: A systematic review of randomized controlled trials. J Manipulative Physiol Ther 2011;34:483-496. 
A32. van den Dolder PA, Ferreira PH, Refshauge KM. Effectiveness of soft tissue massage and exercise for the treatment of nonspecific shoulder pain: A systematic review with meta-analysis. Br J Sports Med 2014;48:1216-1226.

A33. Cheng YH, Huang GC. Efficacy of massage therapy on pain and dysfunction in patients with neck pain: A systematic review and meta-analysis. Evid Based Complement Alternat Med 2014;2014:204360.

A34. Ezzo J, Haraldsson BG, Gross AR, et al. Massage for mechanical neck disorders: A systematic review. Spine 2007;32:353-362.

A35. Kukimoto Y, Ooe N, Ideguchi N. The effects of massage therapy on pain and anxiety after surgery: A systematic review and meta-analysis. Pain Manag Nurs 2017;18:378-390.

A36. Lee PL, Tam KW, Yeh ML, Wu WW. Acupoint stimulation, massage therapy and expressive writing for breast cancer: A systematic review and meta-analysis of randomized controlled trials. Complement Ther Med 2016;27:87-101.

A37. Yeun YR. Effectiveness of massage therapy for shoulder pain: A systematic review and meta-analysis. J Phys Ther Sci 2017; 29:936-940.

A38. Yuan SL, Matsutani LA, Marques AP. Effectiveness of different styles of massage therapy in fibromyalgia: A systematic review and meta-analysis. Man Ther 2015;20:257-264.

A39. Ernst E. Massage therapy for cancer palliation and supportive care: A systematic review of randomised clinical trials. Support Care Cancer 2009;17:333-337.

A40. Ranjbaran M, Khorsandi M, Matourypour P, Shamsi M. Effect of massage therapy on labor pain reduction in primiparous women: A systematic review and meta-analysis of randomized controlled clinical trials in Iran. Iran J Nurs Midwifery Res 2017;22:257-261.

A41. Ajimsha MS, Al-Mudahka NR, Al-Madzhar JA. Effectiveness of myofascial release: Systematic review of randomized controlled trials. J Bodyw Mov Ther 2015;19:102-112.

A42. Ernst E. Massage therapy for low back pain: A systematic review. J Pain Symptom Manage 1999;17:65-69.

A43. Keeratitanont K, Jensen MP, Chatchawan U, Auvichayapat P. The efficacy of traditional Thai massage for the treatment of chronic pain: A systematic review. Complement Ther Clin Pract 2015;21:26-32.

A44. Pan CX, Morrison RS, Ness J, et al. Complementary and alternative medicine in the management of pain, dyspnea, and nausea and vomiting near the end of life. A systematic review. J Pain Symptom Manage 2000;20:374-387.

A45. Lin YC, Wan L, Jamison RN. Using integrative medicine in pain management: An evaluation of current evidence. Anesth Analg 2017; 125:2081-2093.

A46. Richards KC, Gibson R, Overton-McCoy AL. Effects of massage in acute and critical care. AACN Clin Issues 2000;11:77-96.

A47. Barreto DM, Batista MVA. Swedish massage: A systematic review of its physical and psychological benefits. Adv Mind Body Med 2017;31:16-20.

A48. Sut N, Kahyaoglu-Sut H. Effect of aromatherapy massage on pain in primary dysmenorrhea: A meta-analysis. Complement Ther Clin Pract 2017;27:5-10.

A49. Kong L, Bannuru RR, Yuan W, et al. Therapeutic massage on pain relief for fibromyalgia: A systematic review and metaanalysis. Arthritis Rheum 2011;63:2011. 